\title{
Understanding the Asian summer monsoon response to greenhouse warming: the relative roles of direct radiative forcing and sea surface temperature change
}

\author{
Xiaoqiong $\mathrm{Li}^{1}$ (I) Mingfang Ting ${ }^{2}$
}

Received: 10 March 2016 / Accepted: 26 November 2016

(C) Springer-Verlag Berlin Heidelberg 2016

\begin{abstract}
Future hydroclimate projections from state-ofthe-art climate models show large uncertainty and model spread, particularly in the tropics and over the monsoon regions. The precipitation and circulation responses to rising greenhouse gases involve a fast component associated with direct radiative forcing and a slow component associated with sea surface temperature (SST) warming; the relative importance of the two may contribute to model discrepancies. In this study, regional hydroclimate responses to greenhouse warming are assessed using output from coupled general circulation models in the Coupled Model Intercomparison Project-Phase 5 (CMIP5) and idealized atmospheric general circulation model experiments from the Atmosphere Model Intercomparison Project. The thermodynamic and dynamic mechanisms causing the rainfall changes are examined using moisture budget analysis. Results show that direct radiative forcing and SST change exert significantly different responses both over land and ocean. For most part of the Asian monsoon region, the summertime rainfall changes are dominated by the direct $\mathrm{CO}_{2}$ radiative effect through enhanced monsoon circulation. The response to SST warming shows a larger model spread compared to direct radiative forcing, possibly due to the cancellation between the thermodynamical and dynamical components. While the thermodynamical response
\end{abstract}

Lamont-Doherty Earth Observatory contribution number 8078.

Xiaoqiong $\mathrm{Li}$

xqli@1deo.columbia.edu

1 Department of Earth and Environmental Sciences and Lamont-Doherty Earth Observatory, Columbia University, 61 Rt. 9W, Palisades, NY 10964, USA

2 Lamont-Doherty Earth Observatory, Columbia University, 61 Rt. 9W, Palisades, NY 10964, USA of the Asian monsoon is robust across the models, there is a lack of consensus for the dynamical response among the models and weak multi-model mean responses in the CMIP5 ensemble, which may be related to the multiple physical processes evolving on different time scales.

Keywords Climate change - Asian monsoon . Greenhouse warming $\cdot$ Radiative forcing $\cdot$ Sea surface temperature

\section{Introduction}

It is now widely accepted that the global hydrological cycle will become more intensified in a warmer climate, as a consequence of the increase in tropospheric water vapor following the Clausius-Clapeyron relationship, leading to the so-called "wet-get-wetter, dry-get-dryer" pattern of change (Held and Soden 2006). Because of energetic constraints (Takahashi 2009; O'Gorman et al. 2012), the rate of precipitation increase is less than the rate of water vapor, and tropical atmospheric circulation weakens as climate warms (Held and Soden 2006; Vecchi and Soden 2007). However on the regional scale, hydroclimate projections from state-of-the-art climate models show large uncertainty and model spread, particularly in the tropics and over the monsoon regions (Turner and Annamalai 2012; Christensen et al. 2014). The "warmer-get-wetter" mechanism has been proposed to explain the spatial distribution of rainfall change in the tropics, relating to sea surface temperature (SST) pattern (Xie et al. 2010; Chadwick et al. 2013; Ma and Xie 2013). Kent et al. (2015) find that the uncertainty of regional precipitation change in the tropics is predominantly related to spatial shifts in convection and convergence, associated with SST pattern and land-sea thermal 
contrast changes. Using a set of atmospheric general circulation models (AGCMs), He et al. (2014) show that SST pattern is not the dominated factor of atmospheric circulation and precipitation change, with most of its effects confined to equatorial oceans.

The Asian summer monsoon precipitation is projected to enhance under greenhouse warming, dominated by the "wet-get-wetter" thermodynamic mechanism (Kamae et al. 2014a; Wang et al. 2014; Li et al. 2015). On the other hand, dynamical changes related to atmospheric circulation are relatively weak with a low model-agreement (Endo and Kitoh 2014; Li et al. 2015). As highlighted by Xie et al. (2015), atmospheric circulation is the major source of uncertainty in regional rainfall projection. Thus the weak and diverging monsoon circulation response among the models may contribute largely to the uncertainty in monsoon rainfall projections, which is further complicated by other factors such as natural variability ( $\mathrm{Li}$ and Ting 2015) and aerosol effects (Lau et al. 2006; Bollasina et al. 2011; Li et al. 2015).

The response of the climate system to rising greenhouse gases (GHGs) can be through both direct radiative effect and indirect effect via SST change. The direct radiative effect of $\mathrm{CO}_{2}$ represents a fast adjustment of the atmosphere before surface warming occurs, and the indirect effect refers to the slow component induced by subsequent SST warming. From the perspective of the perturbation energy budget of the troposphere (Mitchell et al. 1987; Allen and Ingram 2002): without substantial changes in surface temperature, the fast response associated with increasing $\mathrm{CO}_{2}$ causes a net decrease in radiative cooling and thus reduces the intensity of the hydrological cycle; the slow response due to tropospheric warming, however, causes enhanced radiative cooling that scales approximately with surface temperature change. Thus in climate model simulations, the relative importance of the fast and slow responses may result in discrepancies in how hydroclimate responds to GHG warming.

Recent studies have further shown that the direct radiative forcing of $\mathrm{CO}_{2}$ and SST warming may cause different responses in tropical circulation (Ma et al. 2012; He and Soden 2015a), summertime Pacific anticyclone and the Asian monsoon cyclone (Shaw and Voigt 2015), and midlatitude jets (Grise and Polvani 2014). For tropical rainfall and circulation, Bony et al. (2013) find that a large fraction of the long-term regional precipitation change can be explained by the direct atmospheric radiative response that occurs shortly after an abrupt $\mathrm{CO}_{2}$ increase, independent of surface warming. On the contrary, Chadwick et al. (2014) argue that the fast dynamical precipitation response as shown in Bony et al. (2013) is dominated by surface warming patterns rather than the direct radiative effect. Several studies have shown that the direct radiative forcing and
SST change exert different effects onto the land-sea thermal contrast changes, which then influence the atmospheric thermodynamic structures and circulation patterns (e.g. Joshi et al. 2008; Kamae et al. 2014b). For example, Shaw and Voigt (2015) find significant compensating effects of the two on the summertime Asian monsoon cyclone, Pacific anticyclone and Pacific jet stream, associated with the opposite responses in land-sea equivalent potential temperature contrasts.

Regional climate information under global warming is urgently needed for climate adaptation and socio-economic planning in various sectors, such as water resources, agriculture, and public health, particularly for the densely populated Asian monsoon regions (e.g. Kumar et al. 2004). However reliable predictive information remains a challenge due to the large uncertainty and discrepancy in climate model projections. On one hand, the current generation of coupled general circulation models (CGCMs) still have difficulty in simulating the present-day monsoon climatology (Turner and Annamalai 2012). On the other hand, the often-compensating effects of multiple processes may cause a weak total response and discrepancy among models. It is important to untangle the different physical pathways by which anthropogenic forcing may impact regional hydroclimate and determine their contribution to model uncertainties. Idealized AGCM experiments with prescribed SSTs have been proven to be a useful tool in decomposing the different components (e.g. Mitchell 1983; Mitchell et al. 1987; Hansen et al. 1997; Deser and Phillips 2009; Bala et al. 2010).

In this paper, we examine the hydroclimate response to rising GHGs with a focus on the Asian summer (JuneAugust seasonal mean, JJA) monsoon. We utilize a set of climate model simulations including coupled model projections for the twenty-first century and idealized atmosphere-only climate change experiments with prescribed atmospheric conditions and SSTs. We aim to distinguish the relative roles of atmospheric radiative forcing and ocean-atmosphere interactions, and address the arising uncertainties in model projections. While the recent work by Shaw and Voigt (2015) demonstrates the opposing dynamical responses (defined using the dynamic component of the moisture flux convergence) of the two over Asia and the Pacific, we provide a detailed quantification of the changes for the South and East Asian monsoon regions. We also emphasize the opposing effect of the thermodynamic and dynamic components of the moisture flux convergence response to SST warming, which Shaw and Voigt (2015) presented in one of their supplementary figures without any discussion. We further present the possible contributions of the uncertainty and model spread within the context of CGCMs (CMIP5 models). The model simulations and methodology are described in Sect. 2. Section 3 presents 
the precipitation change forced by rising $\mathrm{CO}_{2}$, separating into the relative effects of direct radiative forcing and SST warming. Section 4 provides a detailed analysis on the thermodynamic and dynamic mechanisms. In Sect. 5, we discuss the uncertainties in future monsoon projections. The main conclusions are summarized in Sect. 6.

\section{Data and methods}

\subsection{Coupled model simulations and idealized experiments}

To examine the projected hydroclimate change in response to greenhouse warming, we used of a set of model simulations including CGCMs and idealized AGCM experiments. For coupled model simulations, we used monthly output from 35 Coupled Model Intercomparison Project-Phase 5 (CMIP5) models (Taylor et al. 2012) under the high-end representative concentration pathway 8.5 (rcp8.5) emission scenario. All available realizations with sufficient variables were analyzed, with a total of 71 . To separate the total response into fast and slow components related to direct atmospheric radiative effect and SST warming, respectively, we used outputs from the Atmospheric Model Intercomparison Project (AMIP) experiments. As part of the CMIP5 archive, the AMIP simulations are idealized AGCM experiments with prescribed SST and sea ice concentration. The following experiments were analyzed: (1) the control simulation (CTRL, called "amip" in the CMIP5 archive), run with observed SST and sea ice concentration from 1979 to 2008; (2) quadrupling $\mathrm{CO}_{2}$ radiative forcing experiment $\left(4 \times \mathrm{CO}_{2}\right.$, "amip $4 \times \mathrm{CO}_{2}$ " in the CMIP5 archive), same SST and sea ice as CTRL, but with quadrupled atmospheric $\mathrm{CO}_{2}$ concentration; (3) uniform $4 \mathrm{~K}$ warming experiment $(+4 \mathrm{~K}$, "amip4K" in the CMIP5 archive), same $\mathrm{CO}_{2}$ concentration as CTRL, but adding a uniform +4K SST anomaly globally. The fast (slow) response is quantified as the difference of the 30 -year climatology between $4 \times \mathrm{CO}_{2}(+4 \mathrm{~K})$ and CTRL.

The AMIP simulations also provide another set of experiments using the SST pattern derived from CMIP3 models under the A1B scenario at the end of the twenty-first century ("amipFuture"), as compared to a uniform warming in the $+4 K$ experiment. Results show that although there are regional differences between the two over the Indian Ocean, southwestern India and the Indonesian Seas, the large-scale responses do not exhibit significant differences (not shown). The choice to use "amip4K" is to emphasize the larger contribution from uniform warming as compared to the SST spatial structure, while using "amipFuture" the two components cannot be clearly distinguished.

The use of atmosphere-only model experiments has its caveats due to the highly idealized design settings such as the obvious lack of coupling with the ocean. The direct radiative effect of increasing GHGs is closely coupled to the SST warming, thus only accounting for the radiative effect of the GHG increase through land warming while no ocean warming is allowed is artificial, as addressed by other similar studies (e.g. Deser and Phillips 2009). Nevertheless, the time taken for the ocean surface to warm up is longer than that for the land surface, and the direct effect here can be treated as a fast response to a switched-on $\mathrm{CO}_{2}$ quadrupling. This type of analysis has been proven to be useful in determining the underlying physical mechanisms in several previous studies (e.g. Grise and Polvani 2014; He and Soden 2015a; Shaw and Voigt 2015). He and Soden (2015b) further show that anthropogenic climate change in CGCMs can be well reproduced in AGCMs, thus lend further support of using the AGCM approach.

The AMIP experiments are available for 11 out of the 35 models used for rep8.5 simulations in this study, with monthly data for 30 years in length. We used the first realization of 10 AGCMs (FGOALS-g2 was not used due to its unrealistic simulation of climatological monsoon rainfall, see "Appendix"). Details of the model simulations are provided in Table 1. All model outputs were interpolated to a $1^{\circ} \times 1^{\circ}$ spatial resolution in the land-only calculations to allow a better representation of the coastlines, and a $2^{\circ} \times 2^{\circ}$ spatial resolution to illustrate the spatial patterns on a global scale (a comparison shows that the change of resolution has little effect on the results).

\subsection{Moisture budget analysis}

We use the atmospheric moisture budget equation (Trenberth and Guillemot 1995) to analyze the changes in the hydrological cycle, following Li et al. (2015). In steady state, precipitation minus evaporation $(P-E)$ balances the convergence of the vertically integrated atmospheric moisture flux, which can be expressed in pressure coordinates as follows:

$\bar{P}-\bar{E}=-\frac{1}{g \rho_{w}} \nabla \cdot \overline{\int_{0}^{p_{s}} \mathbf{u} q d p}$,

where $P$ is precipitation, $E$ is evaporation, $g$ is gravitational acceleration, $\rho_{w}$ is the density of water, $p$ is pressure and $p_{s}$ surface pressure, $\mathbf{u}$ is the horizontal wind vector $(\mathbf{u}=u \mathbf{i}+v \mathbf{j}$ ), $q$ is specific humidity. Overbars represent monthly mean values. The vertical integral in Eq. (1) is calculated as the sum over pressure levels, so we rewrite Eq. (1) as:

$\bar{P}-\bar{E} \approx-\frac{1}{g \rho_{w}} \nabla \cdot \sum_{k=1}^{K} \overline{\mathbf{u}_{k} q_{k}} \overline{\Delta p}_{k}$

where $k$ is the vertical level with a total of $K, \Delta p$ is the pressure thickness. Here the calculation is performed on 
Table 1 List of CMIP5 and AMIP models, scenarios, and the number of realizations used in the study

\begin{tabular}{|c|c|c|c|c|}
\hline Model & $\mathrm{rcp} 8.5$ & CTRL & $4 \times \mathrm{CO}_{2}$ & $+4 \mathrm{~K}$ \\
\hline ACCESS1-0 & 1 & - & - & - \\
\hline ACCESS1-3 & 1 & - & - & - \\
\hline bcc-csm1-1 & 1 & 1 & 1 & 1 \\
\hline bcc-csm1-1-m & 1 & - & - & - \\
\hline BNU-ESM & 1 & - & - & - \\
\hline CanESM2 & 5 & 1 & 1 & 1 \\
\hline CCSM4 & 6 & - & - & - \\
\hline CESM1-BGC & 1 & - & - & - \\
\hline CESM1-CAM5 & 2 & - & - & - \\
\hline CMCC-CESM & 1 & - & - & - \\
\hline CMCC-CM & 1 & - & - & - \\
\hline CMCC-CMS & 1 & - & - & - \\
\hline CNRM-CM5 & 5 & 1 & 1 & 1 \\
\hline CSIRO-Mk3-6-0 & 10 & - & - & - \\
\hline FGOALS-g2 & 1 & - & - & - \\
\hline FIO-ESM & 3 & - & - & - \\
\hline GFDL-CM3 & 1 & - & - & - \\
\hline GFDL-ESM2G & 1 & - & - & - \\
\hline GFDL-ESM2M & 1 & - & - & - \\
\hline GISS-E2-H & 1 & - & - & - \\
\hline GISS-E2-R & 2 & - & - & - \\
\hline HadGEM2-CC & 1 & - & - & - \\
\hline HadGEM2-ES & 4 & 1 & 1 & 1 \\
\hline inmcm4 & 1 & - & - & - \\
\hline IPSL-CM5A-LR & 4 & 1 & 1 & 1 \\
\hline IPSL-CM5A-MR & 1 & - & - & - \\
\hline IPSL-CM5B-LR & 1 & 1 & 1 & 1 \\
\hline MIROC-ESM & 1 & - & - & - \\
\hline MIROC-ESM-CHEM & 1 & - & - & - \\
\hline MIROC5 & 3 & 1 & 1 & 1 \\
\hline MPI-ESM-LR & 3 & 1 & 1 & 1 \\
\hline MPI-ESM-MR & 1 & 1 & 1 & 1 \\
\hline MRI-CGCM3 & 1 & 1 & 1 & 1 \\
\hline NorESM1-M & 1 & - & - & - \\
\hline NorESM1-ME & 1 & - & - & - \\
\hline
\end{tabular}

10 pressure levels from 1000 to $200 \mathrm{hPa}$. We neglect submonthly variations of surface pressure since this introduces no significant error (Seager and Henderson 2013).

We then denote departures from monthly means with primes:

$\mathbf{u}=\overline{\mathbf{u}}+\mathbf{u}^{\prime}, \quad q=\bar{q}+q^{\prime}$,

and the monthly mean moisture flux can be expressed as:

$\overline{\mathbf{u} q}=\overline{\mathbf{u}} \bar{q}+\overline{\mathbf{u}^{\prime} q^{\prime}}$.

Separating the moisture flux convergence term into contributions of mean moisture convergence (MC) and the submonthly transient eddies (TE), Eq. (2) can be written as:

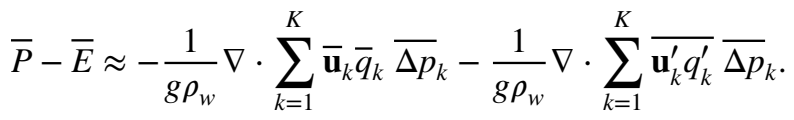

Due to limitations in daily data availability for most of the AMIP models, the transient eddy component is approximated using the difference between $P-E$ and the mean moisture convergence, thus includes a residual term. Seager and Henderson (2013) have shown that the error arising from closing the moisture budget equation, i.e., differences between $P-E$ and the vertically integrated moisture convergence is small and thus can be neglected. Furthermore, since the response to the given forcing is quantified as the climatological difference between the forced and control simulations, the residual term is largely eliminated.

To quantify the effect of the given forcing $\left(4 \times \mathrm{CO}_{2}\right.$ or $+4 \mathrm{~K})$, we introduce a second overbar to denote the 30-year climatological mean, and a hat above an overbar to denote the departure of the monthly mean from the climatological value:

$\overline{\mathbf{u}}=\overline{\overline{\mathbf{u}}}+\hat{\overline{\mathbf{u}}}, \quad \bar{q}=\overline{\bar{q}}+\hat{\bar{q}}$.

We also define

$\delta \overline{\overline{(.)}}=\overline{\overline{(.)}}_{F}-\overline{\overline{(.)}}_{C}$

to represent the climatological difference between the forced (subscript $F$ ) and control (subscript $C$ ) experiments. Then the response of the mean moisture convergence to the forcing can be derived as follows:

$$
\begin{aligned}
& \delta \overline{\overline{M C}}=\left(-\frac{1}{g \rho_{w}} \overline{\overline{\sum_{k=1}^{K} \overline{\mathbf{u}}_{k, F} \bar{q}_{k, F} \overline{\Delta p}_{k, F}}}\right) \\
& -\left(-\frac{1}{g \rho_{w}} \overline{\bar{\nabla} \cdot \sum_{k=1}^{K} \overline{\mathbf{u}}_{k, C} \bar{q}_{k, C} \overline{\Delta p}_{k, C}}\right) \\
& =\left(-\frac{1}{g \rho_{w}} \nabla \cdot \overline{\sum_{k=1}^{K}\left(\overline{\overline{\mathbf{u}}}_{k, C}+\hat{\overline{\mathbf{u}}}_{k, F}\right)\left(\overline{\bar{q}}_{k, C}+\widehat{\bar{q}}_{k, F}\right) \overline{\Delta p}_{k, F}}\right)
\end{aligned}
$$

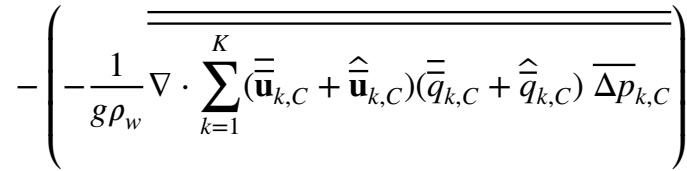

$$
\begin{aligned}
& \approx-\frac{1}{g \rho_{w}} \nabla \cdot \sum_{k=1}^{K} \overline{\overline{\mathbf{u}}}_{k, C} \delta \overline{\bar{q}}_{k} \overline{\overline{\Delta p}}_{k}-\frac{1}{g \rho_{w}} \nabla \cdot \sum_{k=1}^{K} \delta \overline{\overline{\mathbf{u}}}_{k} \overline{\bar{q}}_{k, C} \overline{\overline{\Delta p}}_{k} \\
& =\delta \overline{\overline{T H}}+\delta \overline{\overline{D Y}} \text {. }
\end{aligned}
$$


$\delta T H$ represents the thermodynamic component, with circulation fixed at its climatological value in the CTRL experiment, thus involving only changes in specific humidity; and $\delta D Y$ represents the dynamic component, with specific humidity fixed at its climatological value in the CTRL experiment, thus involving only changes in circulation. In the derivation of Eq. (8), the approximation originates from ignoring (1) the quadratic term involving covariances of departures from climatological values (small compared to the other terms); and (2) surface pressure variations that cause differences between $\Delta p_{k, F}$ and $\Delta p_{k, C}$ (which has been shown in Seager and Henderson (2013) to introduce little additional error).

\section{Precipitation response to future GHG forcing}

\subsection{Projected 21st century monsoon rainfall change in CMIP5 coupled models}

We start with examining the projected summer monsoon rainfall change for the 21 st century under the rep8.5 scenario in all the realizations of the 35 coupled CMIP5 models. Figure 1 shows the linear trend of area averaged land precipitation from 2006 to 2099 for India $\left(5^{\circ} \mathrm{N}-30^{\circ} \mathrm{N}, 70^{\circ} \mathrm{E}\right.$ $-90^{\circ} \mathrm{E}$, Fig. 1a) and eastern China $\left(20^{\circ} \mathrm{N}-40^{\circ} \mathrm{N}, 105^{\circ} \mathrm{E}\right.$ $-125^{\circ} E$, Fig. 1b). The shaded bars show the $95 \%$ confidence intervals based on 2-sided Student's t test applied onto detrended data, thus indicating the interannual range of the trend due to natural variability. Generally speaking, the majority of the models predict a stronger monsoon for both India and eastern China, while the magnitude differs among individual models. A few models, however, show a weak signal or drying trend. The group of models with weak or opposing signs also differs for India and eastern China.

The multi-model mean (MMM), plotted at the bottom in black, gives a wetting trend for both regions. In calculating the MMM, we first computed each model's ensemble average, and then averaged across the 35 models. This wetting trend is consistent with previous studies suggesting an intensified monsoon (Endo and Kitoh 2014; Li et al. 2015), with stronger wetting over India than eastern China. This may be related to the larger discrepancy among individual models over eastern China, with more models showing insignificant weak responses. The spatial pattern of the change displays an overall uniform wetting, as shown in Fig. 1d in Li et al. (2015).

Figure 1 indicates that while most models show an intensified Asian monsoon rainfall, there is substantial model (a) P trend JJA 2006-2099 CMIP5 rcp85 IND

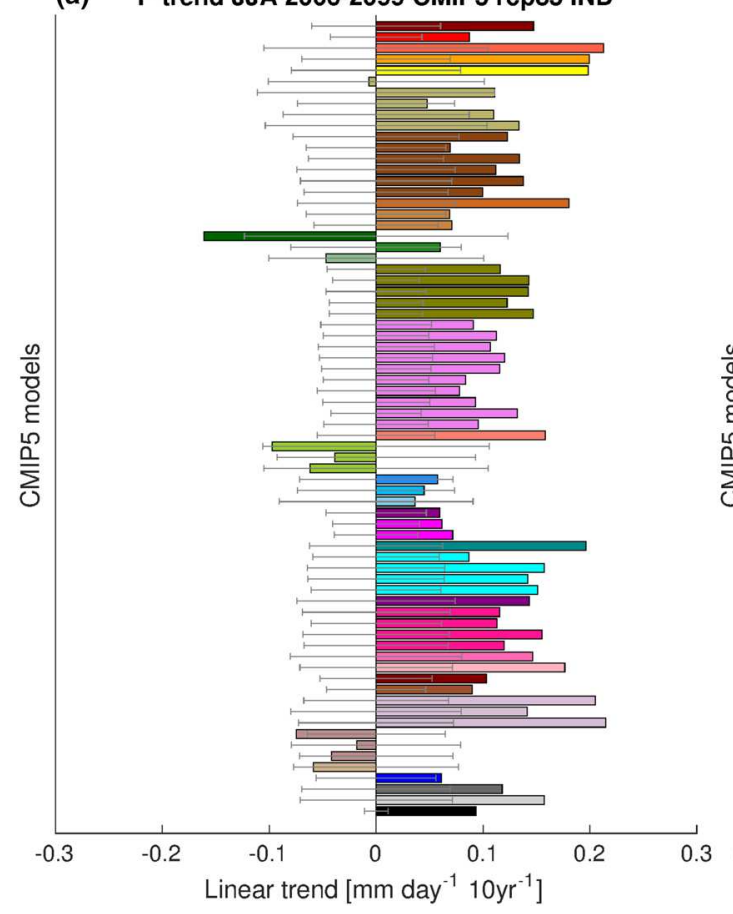

Fig. 1 Linear trend of area averaged land precipitation in 35 CMIP5 models under the rcp8.5 scenario from 2006 to 2099 for a India $\left(5^{\circ} \mathrm{N}-30^{\circ} \mathrm{N}, 70^{\circ} \mathrm{E}-90^{\circ} \mathrm{E}\right)$ and b East China $\left(20^{\circ} \mathrm{N}-40^{\circ} \mathrm{N}, 105^{\circ} \mathrm{E}\right.$ $\left.-125^{\circ} \mathrm{E}\right)$. The black bar at the bottom shows the multi-model mean (b) P trend JJA 2006-2099 CMIP5 rcp85 ECHN

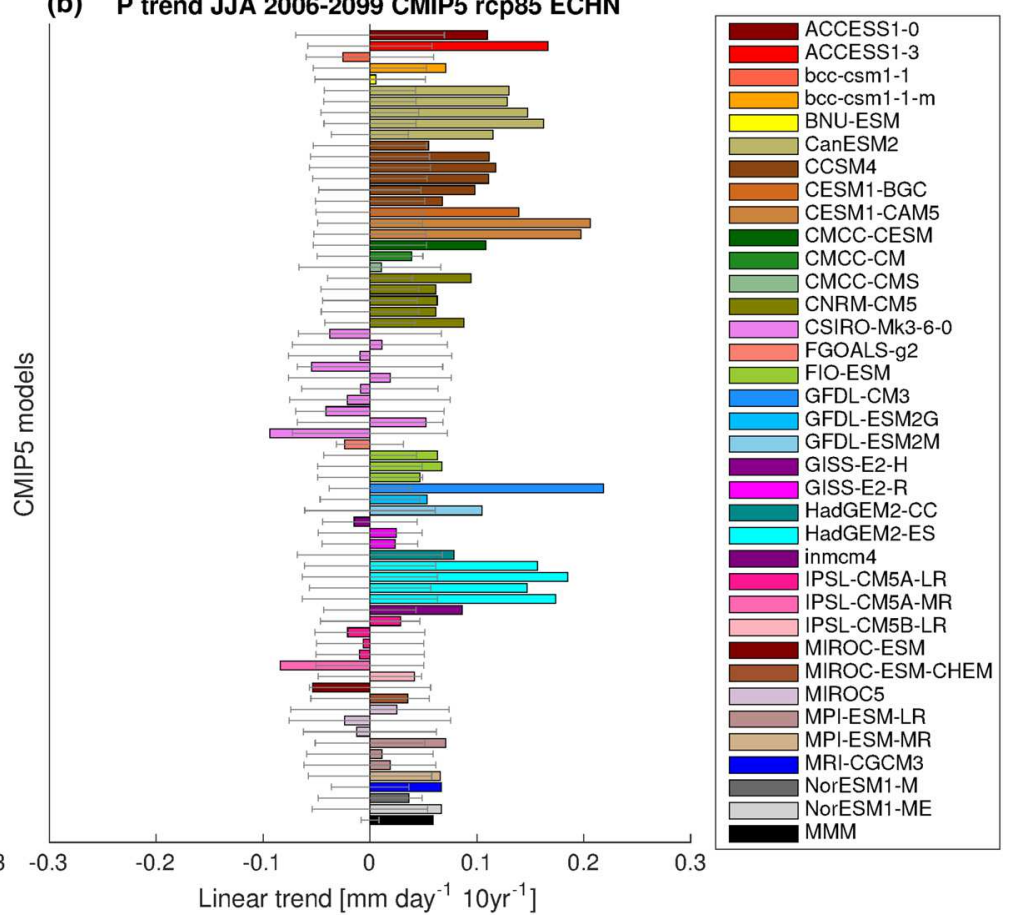

(MMM). The shaded bars show the 95\% confidence intervals based on 2-sided Student's t test applied onto detrended data. Units are $\mathrm{mm} \mathrm{day}^{-1} 10$ years $^{-1}$ 
spread. It is not clear whether the intensification as well as the spread is caused mainly by the fast or slow responses, or, caused more by thermodynamic versus dynamic mechanisms, which will be explored in the following sections.

\subsection{Effects of $\mathrm{CO}_{2}$ radiative forcing and SST warming in AMIP experiments}

In order to decompose the different physical processes contributing to the overall wetting and model spread as shown in Fig. 1, we use the AMIP experiments to analyze the relative roles of the fast response due to direct radiative forcing and the slow response due to SST change. Since rcp8.5 is the "business as usual" scenario with the highest GHG emissions and gradually phasing out anthropogenic aerosol emissions, the total response is dominated by the $\mathrm{CO}_{2}$ forcing. A detailed estimate of the radiative forcing can be found in Shindell et al. (2013).

Figure $2 \mathrm{a}, \mathrm{b}$ shows the precipitation response $(\delta \overline{\bar{P}})$ for $4 \times \mathrm{CO}_{2}$ and $+4 \mathrm{~K}$, respectively. Here we show the global pattern to better identify the large-scale changes. The direct radiative forcing and SST warming exert significantly different responses both over the land and ocean. Over the ocean, the fast response (Fig. 2a) displays an overall drying globally, while the slow response (Fig. 2b) shows particularly enhanced wetting over the intertropical convergence zone (ITCZ), the western Pacific warm pool region, and the higher latitudes extending towards the polar regions. The land rainfall response displays significant regional variations in both cases. For regions such as the Mediterranean and western United States, both the fast and slow components contribute towards a drying trend. For the Sahel, on the other hand, the two oppose each other, with the direct radiative effect wetting the Sahel and the SST effect drying the region. For the Asian monsoon, the fast response enhances monsoon rainfall over most regions in China, northern and central India, but reduces rainfall in southern India and Indochina. On the other hand, the slow response dries eastern China and northern India, but has a strong wetting over Indochina, central and southern India, possibly due to oceanic influence extending from the western Pacific warm pool.

The combination of the two responses (adding Fig. 2a, b) is shown in Fig. 2c. As a comparison, Fig. 2d shows the rcp8.5 response using the coupled version for the same 10 models. The rep8.5 response is calculated using (a)

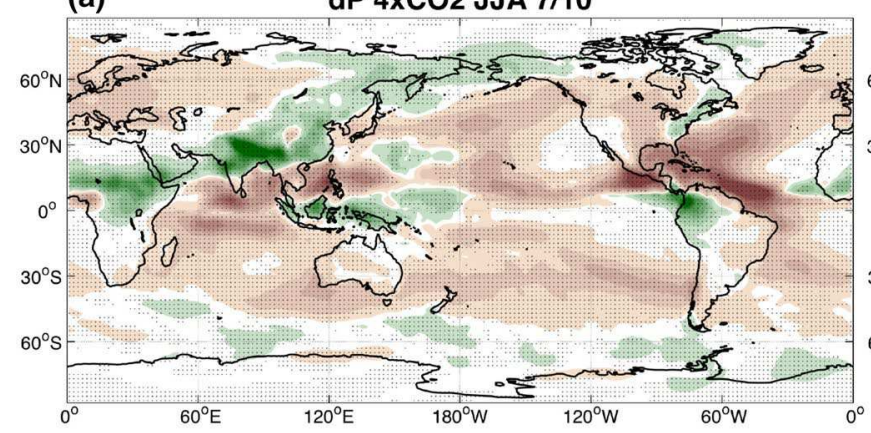

(c)

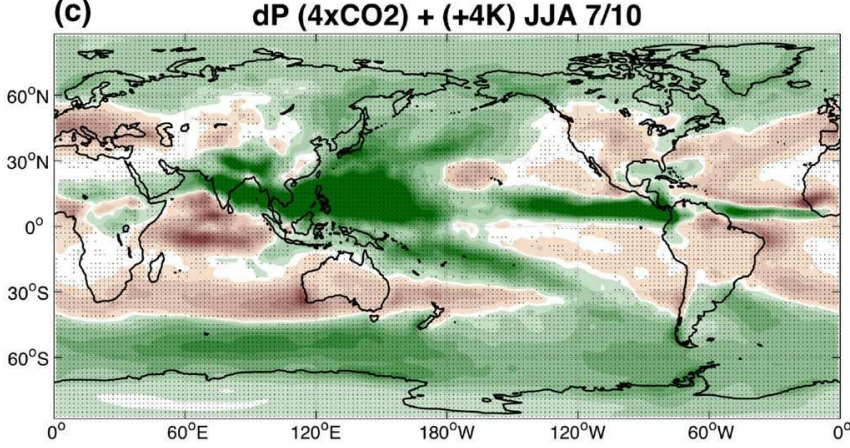

(b)

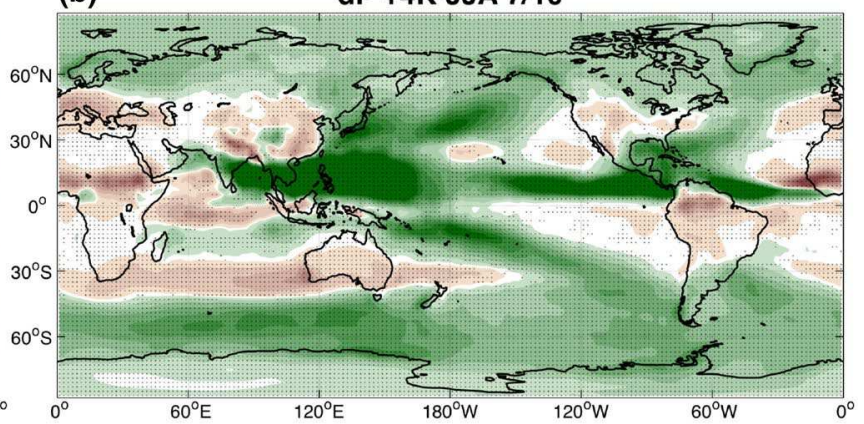

(d)

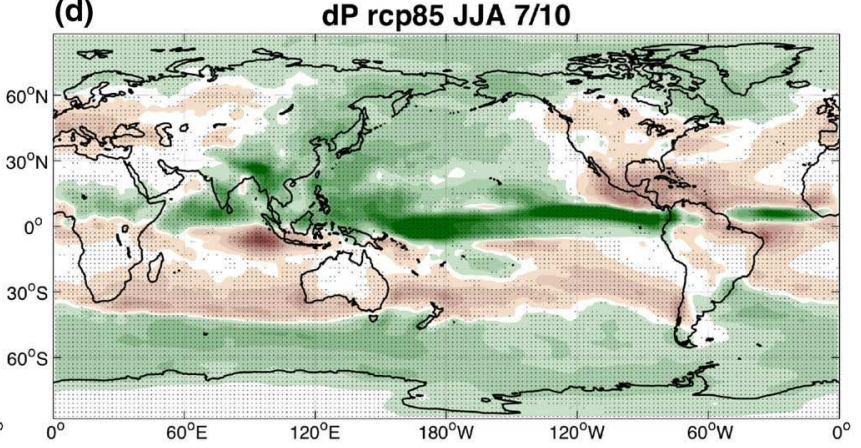

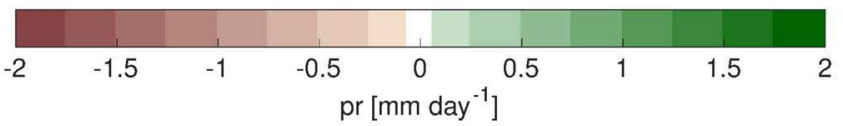

Fig. 2 Precipitation response $\delta \overline{\bar{P}}$ for $\mathbf{a} 4 \times \mathrm{CO}_{2}, \mathbf{b}+4 K, \mathbf{c} 4 \times \mathrm{CO}_{2}$ plus $+4 K$, and $\mathbf{d}$ rcp8.5. Stippling denotes 7 out of 10 models agree on the sign of change. Units are $\mathrm{mm} \mathrm{day}^{-1}$ 
the climatological difference between the 2075-2099 period and 2006-2030 period. Despite the highly idealized settings and differences in forcings, Fig. 2c is able to capture the general large-scale pattern in the CGCMs (Fig. 2d) with a weighted spatial pattern correlation of 0.55 . There are regional differences including an overly wetting in the western tropical Pacific and dry bias in the Indian Ocean in the AGCMs, possibly related to the effects of the SST warming pattern (Xie et al. 2010; He et al. 2014)

Figure $2 \mathrm{c}, \mathrm{d}$ shows that the future total rainfall response to $\mathrm{CO}_{2}$ forcing is a combination of direct radiative effect and SST warming. The SST effect (Fig. 2b) dominates the total response over the ocean. Over land, for the Mediterranean and western United States where the two effects have the same sign, there is a strong drying trend in the combined as well as the coupled response, contributing to a more robust future precipitation projection in these regions (Seager et al. 2007, 2014; Kelley et al. 2012; Christensen et al. 2014). For most part of the Asian monsoon region, the direct radiative effect (Fig. 2a) dominates, resulting in enhanced monsoon rainfall as climate warms, consistent with Bony et al. (2013). However note that the southern part of India as well as Indochina display opposite responses compared to northern India and eastern China, possibly influenced by the surrounding oceans.

\section{Thermodynamic and dynamic mechanisms of $\mathrm{CO}_{2}$-induced rainfall changes: direct radiative forcing versus SST warming}

\subsection{Moisture and circulation}

Why does monsoon precipitation respond differently to direct radiative forcing and SST warming? In this section, we analyze the thermodynamic and dynamic mechanisms contributing to the difference, and compare with the results of Shaw and Voigt (2015). Figure 3a-d show the change of $850 \mathrm{hPa}$ specific humidity and winds for $4 \times \mathrm{CO}_{2}$ and $+4 \mathrm{~K}$. The moisture response is dominated by the strong increase due to SST warming (Fig. 3b), with little change related to direct radiative forcing (Fig. 3a). Atmospheric circulation, on the other hand, shows distinct compensating effects over most regions in the northern hemisphere. In particular, direct radiative forcing (Fig. 3c) shifts the Asian monsoon circulation northward and shows a generally intensified monsoon circulation, which is similar to the response in the coupled models, both rcp8.5 and GHG-only single-forcing simulations (cf. Li et al. 2015; Figs. 4f, 8f); SST warming, on the other hand, weakens the monsoon circulation over Asia (Fig. 3d). Consistent with the $925 \mathrm{hPa}$ stationary eddy streamfunction and $500 \mathrm{hPa}$ vertical motion responses as shown in Shaw and Voigt (2015), direct radiative forcing enhances the Pacific subtropical anticyclone and SST warming weakens it. In the southern hemisphere, the fast and slow components show similar circulation responses, (a)

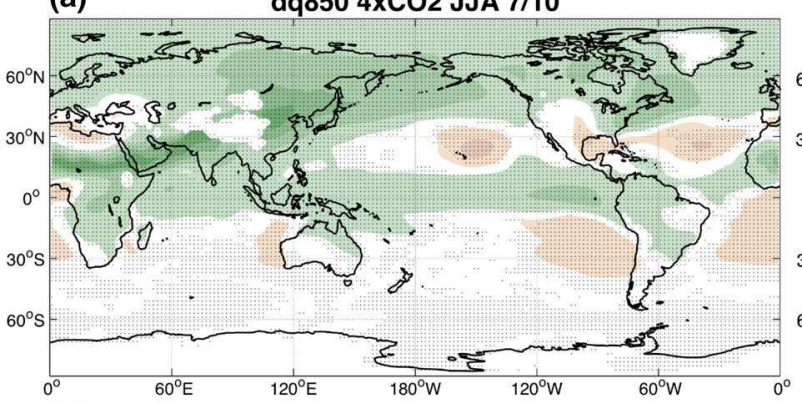

(c)

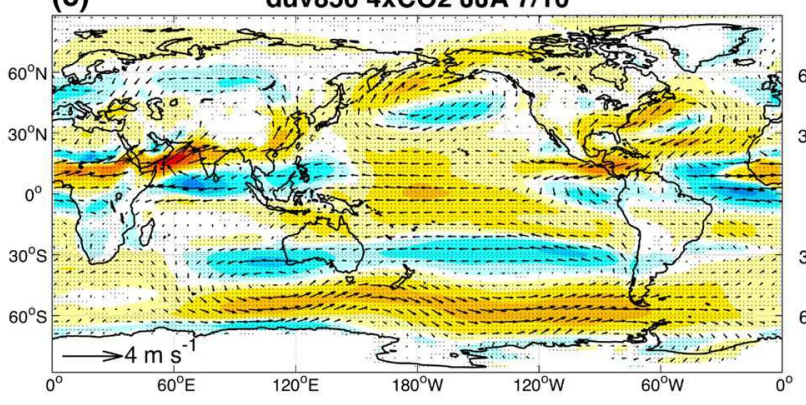

(b)

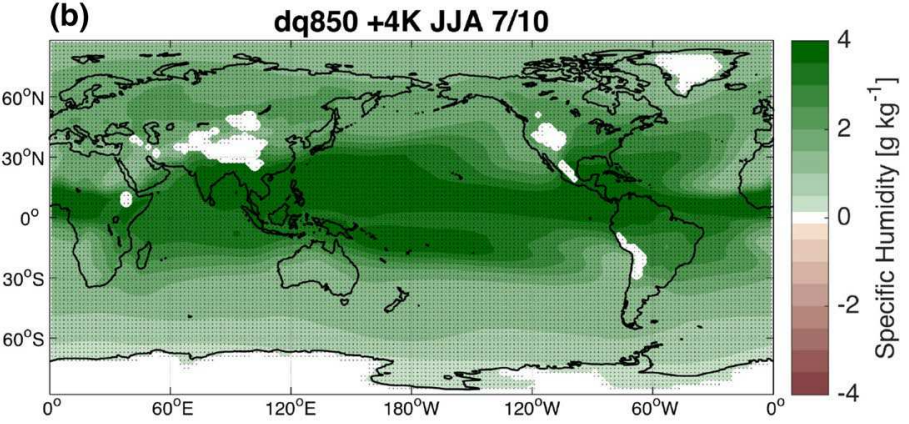

(d)

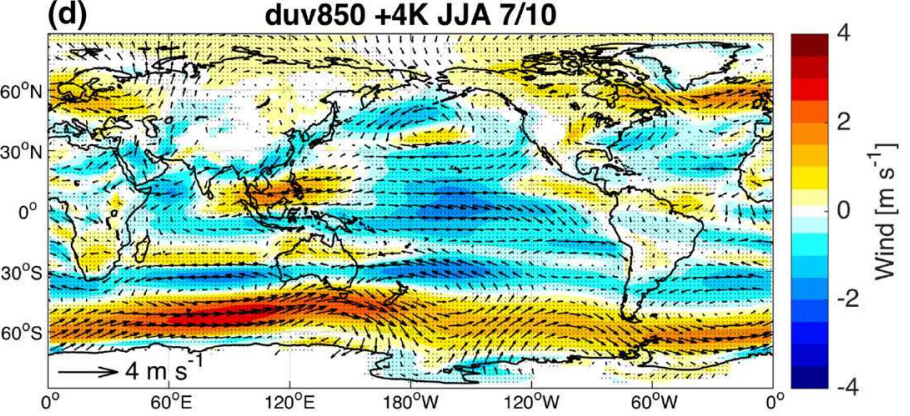

Fig. 3 Response of $850 \mathrm{hPa} \mathbf{a}, \mathbf{b}$ specific humidity $\delta \overline{\bar{q}}$ (units $\mathrm{g} \mathrm{kg}^{-1}$ ) and $\mathbf{c}$, d winds $\delta \overline{\overline{\mathbf{u}}}$ (units m s${ }^{-1}$ ) for a, $\mathbf{c} 4 \times C O_{2}$ and $\mathbf{b}, \mathbf{d}+4 K$. In $\mathbf{c}, \mathbf{d}$, arrows are vectors of the response and shading shows the change in wind speed. Stippling as in Fig. 2 
(a)

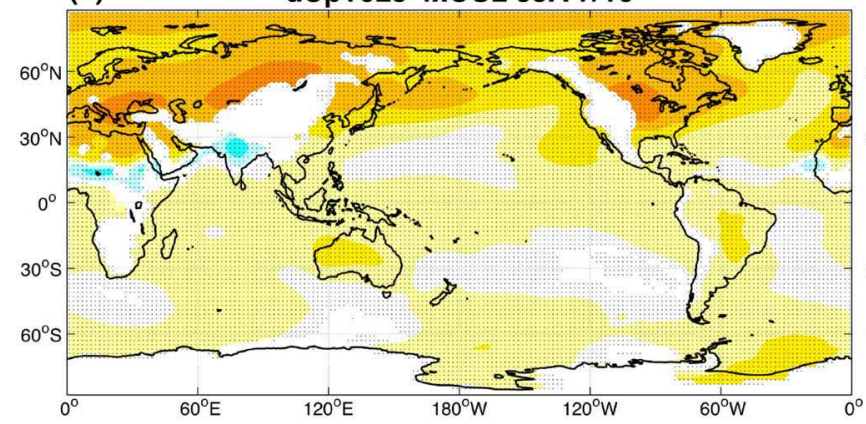

(c)

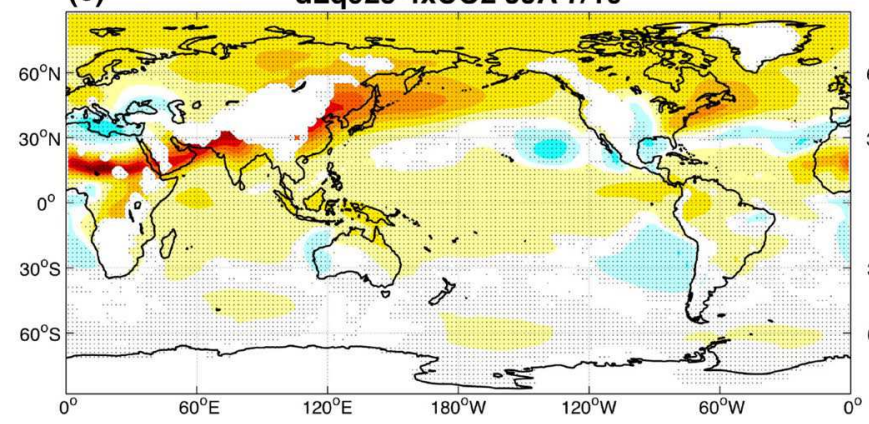

(e)

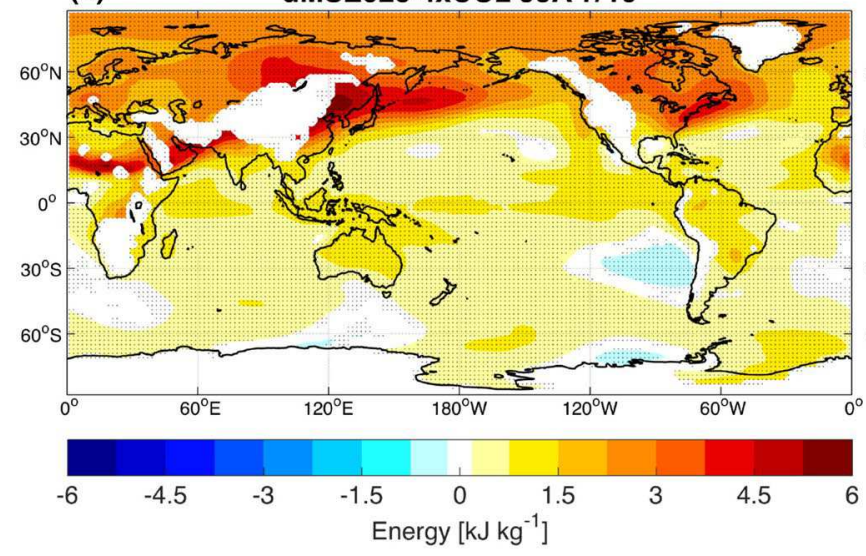

(b)

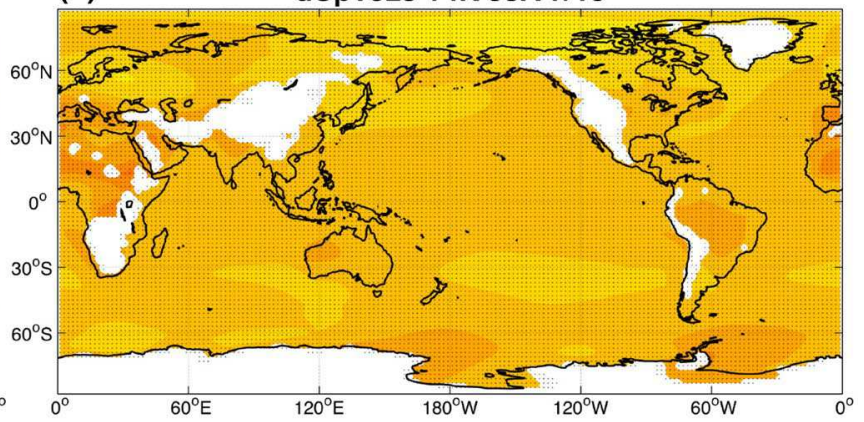

(d)

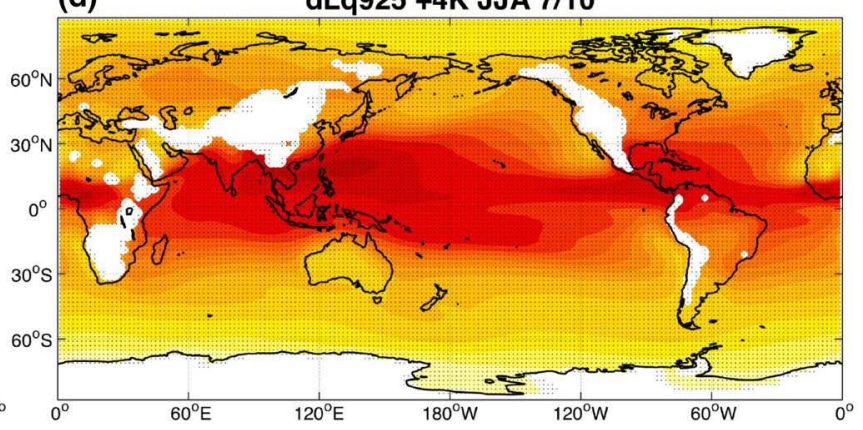

(f)

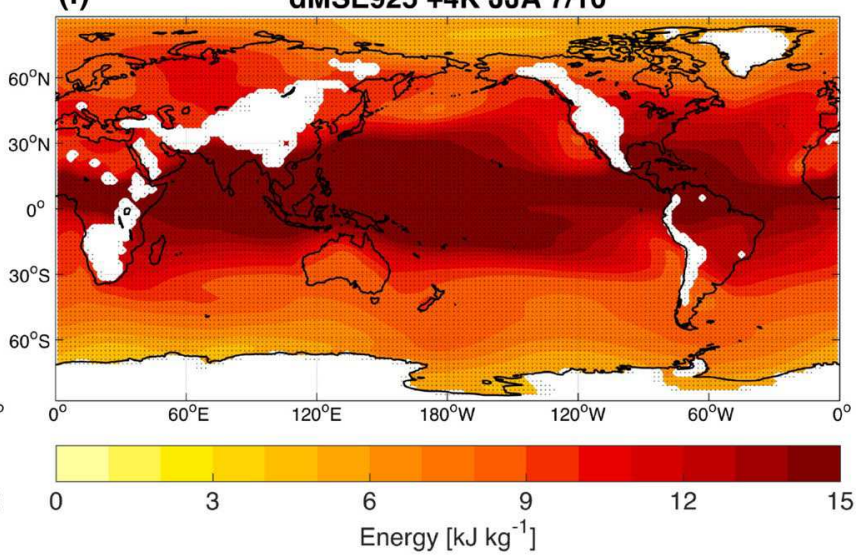

Fig. 4 Response of $925 \mathrm{hPa} \mathbf{a}, \mathbf{b}$ air temperature in energy unit $\delta \overline{\overline{c_{p} T}}, \mathbf{c}, \mathbf{d}$ specific humidity in energy unit $\delta \overline{\overline{L_{v}}}$, and $\mathbf{e}, \mathbf{f}$ moist static energy $\delta \overline{\overline{M S E}}$ for $\mathbf{a}, \mathbf{c}, \mathbf{e} 4 \times \mathrm{CO}_{2}$ and $\mathbf{b}, \mathbf{d}, \mathbf{f}+4 K$. Stippling as in Fig. 2. Units are $\mathrm{kJ} \mathrm{kg}^{-1}$

with a poleward shifted jet stream, consistent with Grise and Polvani (2014).

One possible explanation for the opposite changes in circulation for $4 \times \mathrm{CO}_{2}$ and $+4 \mathrm{~K}$ is the difference in landsea thermal contrast changes (Kamae et al. 2014b; Shaw and Voigt 2015). Figure 4a, b shows the air temperature at $925 \mathrm{hPa}$ (shown in thermodynamic energy unit, $c_{p} T$, where $c_{p}$ is the specific heat of air at constant pressure, $T$ is air temperature) for the $4 \times \mathrm{CO}_{2}$ and $+4 \mathrm{~K}$ experiments. In the $4 \times \mathrm{CO}_{2}$ experiment, land warms more than ocean as the heat capacity of the land is much lower than water. The exception is a cooling trend over southern India in $4 \times \mathrm{CO}_{2}$, possibly induced by increased evaporation (Fig. 5a), although the exact reason remains unclear. In the
$+4 K$ case, there is strong ocean warming, which leads to a greatly moistened lower troposphere (Fig. 3b). Note, however, that land still warms slightly more than ocean in $+4 K$ (Fig. 4b), consistent with Joshi et al. (2008) who propose local feedbacks and the hydrological cycle over land as the mechanism for enhanced land-warming (see also Byrne and O'Gorman 2013). Thus one cannot explain the opposing monsoon circulation response purely based on changes in temperature.

Figure $4 \mathrm{c}, \mathrm{d}$ shows the change in atmospheric moisture (shown in energy unit, $L_{v} q$, where $L_{v}$ is the latent heat of vaporization, $q$ is specific humidity) at $925 \mathrm{hPa}$ for $4 \times \mathrm{CO}_{2}$ and $+4 \mathrm{~K}$. It is clear that the $+4 \mathrm{~K}$ experiment is associated with a much stronger moistening 
(a)
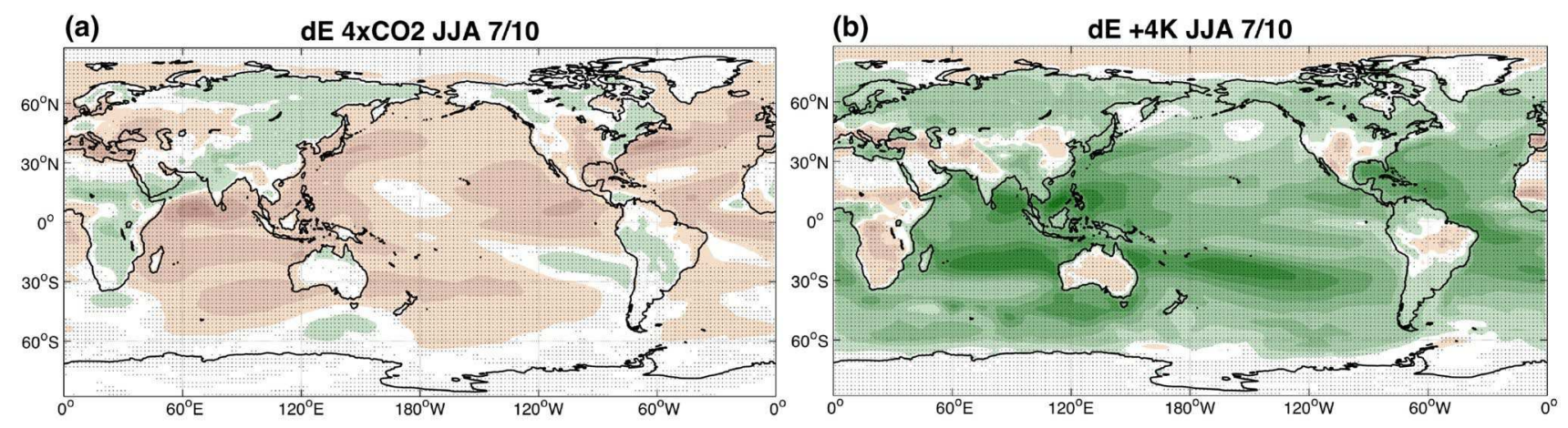

(c)

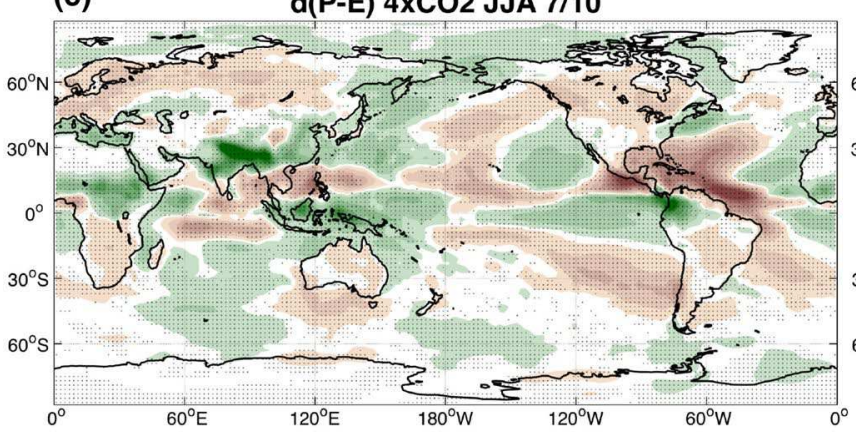

(d)

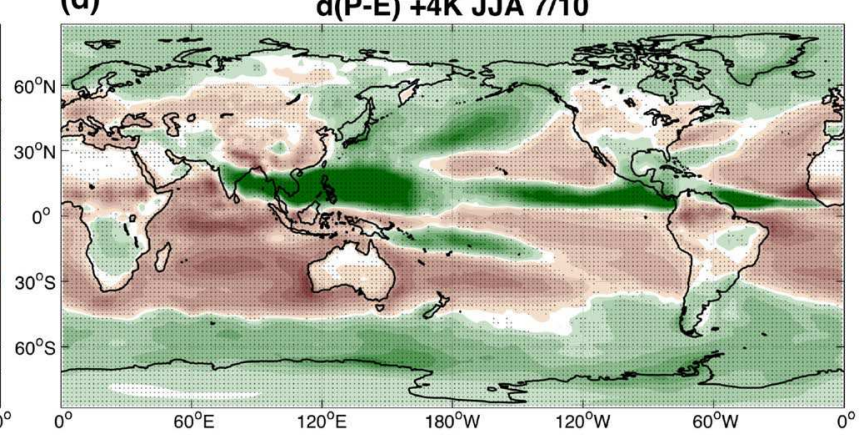

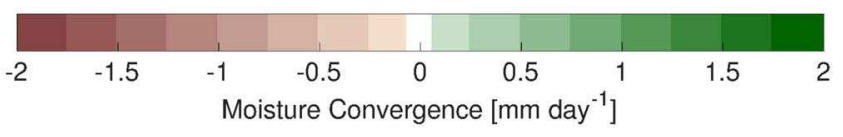

Fig. 5 Response of a, b evaporation $\delta \overline{\bar{E}}$ and c, d precipitation minus evaporation $\overline{\overline{(P-E)}}$ for a, c $4 \times C O_{2}$, b, d $+4 K$. Stippling as in Fig. 2 . Units are mm day ${ }^{-1}$

over ocean than over land (Fig. 4d). There are also significant changes in the moisture component over land for the $4 \times \mathrm{CO}_{2}$ case (Fig. 4c), particularly over the monsoon region as a response to enhanced moisture transport due to stronger monsoon circulation (Fig. 3c). The total moist static energy (MSE) changes are shown in Fig. 4e, f, which combines the effect of temperature and moisture changes (defined as $M S E=c_{p} T+L_{v} q+g Z, g$ is gravity, and $Z$ is the geopotential height; the potential energy change associated with $g Z$ is negligible in this case). Figure 4 suggests that the land-sea moisture contrast is the dominant contributor to the total MSE contrast for the $+4 K$ experiment, and to a large extent, to the $4 \times \mathrm{CO}_{2}$ experiment as well. Our results here indicate that $M S E$ increases more (less) over land than over ocean in $4 \times \mathrm{CO}_{2}(+4 \mathrm{~K})$ experiment, thus enhancing (weakening) the monsoon circulation (Fig. 3c, d). This conclusion is consistent with Shaw and Voigt (2015) using the subcloud equivalent potential temperature. The dominance of land-sea moisture contrasts in the MSE contrasts in $+4 K$ is insensitive to whether SST warming is uniform or not, as it is confirmed using "amipFuture" experiments with patterned SST warming (not shown), suggesting that gradients in SST is not essential in driving the landsea thermodynamic contrasts and monsoon circulation change.

\subsection{The moisture budget}

In this subsection, we further examine the thermodynamic and dynamic mechanisms causing the rainfall changes using moisture budget analysis. The pattern of $P-E$ change, the net change in surface water balance, largely follows the rainfall changes (Fig. 2a, b) for both the direct radiative forcing (Fig. 5c) and SST warming (Fig. 5d), particularly over land. For oceanic regions, evaporation increases greatly due to SST warming (Fig. 5b) but decreases in the $4 \times \mathrm{CO}_{2}$ response (Fig. 5a). The reduction in evaporation in the $4 \times \mathrm{CO}_{2}$ case can be understood through the atmospheric heat budget due to quadrupling $\mathrm{CO}_{2}$ while keeping the SST fixed. On average, the atmosphere cools through longwave radiation, which is largely balanced by latent heat flux into the atmosphere at the surface and thus precipitation (sensible heat flux also contributes, but much less than latent heat flux). The quadrupling of $\mathrm{CO}_{2}$ leads to a decrease in atmospheric radiative cooling due to the anomalous absorption 
of longwave radiation by the atmosphere, which has to be balanced by a reduction in surface latent heat flux into the atmosphere through reduced surface evaporation (Yang et al. 2003; Bala et al. 2008, 2010; Andrews et al. 2009). Over the Asian monsoon region, there are small increases in evaporation over land due to increased precipitation. We will explore further the causes for the change in $P-E$ through the atmospheric moisture budget.

Changes in the mean moisture convergence $(\delta \overline{\overline{M C}})$ and transient eddies $(\delta \overline{\overline{T E}})$ are shown in Fig. 6. In the tropics, $\delta \overline{\overline{M C}}$ (Fig. 6a, b) dominates over $\delta \overline{\overline{T E}}$ (Fig. 6c, d), and agrees well with the $\delta \overline{\overline{(P-E)}}$ pattern (Fig. 5c, d). For the higher latitudes, $\delta \overline{\overline{T E}}$ plays an important role in the $+4 K$ case. In particular, the high latitude wetting trend, suggested by Zhang et al. (2013) to be primarily driven by the increasing poleward atmospheric moisture transport, is dominated by the transient contributions.

To illustrate the change in the surface hydrological cycle and the model spread the Asian monsoon region, Fig. 7 shows the area averaged changes in precipitation, evaporation, $P-E$, and the mean and transient moisture convergence terms over Indian and eastern China for $4 \times \mathrm{CO}_{2}$ (red), $+4 \mathrm{~K}$ (blue) and rcp8.5 (green, quantified as in Fig. 2d), with black dots denoting the MMMs. For both India (Fig. 7a) and eastern China (Fig. 7b), $\delta \overline{\overline{M C}}$ dominates $\overline{\overline{\delta(P-E)}}$ and $\delta \overline{\bar{P}}$, with $\delta \overline{\overline{T E}}$ and $\delta \overline{\bar{E}}$ terms being relatively small across all three types of experiments. In both regions, direct radiative forcing (red) enhances the mean moisture convergence, while SST warming (blue) shows a large spread, with a slightly increased moisture convergence in MMM for India and a slightly decreased moisture convergence for eastern China. The rcp8.5 response (green), although not directly comparable in magnitude, largely follows the sum of the two effects (not shown). Figure 7 also indicates that the enhanced Asian monsoon rainfall in the rcp8.5 scenario is dominated by direct radiative forcing (fast response) rather than the equilibrium response due to SST warming. Also note that the model spread in the $+4 K$ experiment is larger than that in $4 \times \mathrm{CO}_{2}$, suggesting higher uncertainty in the slow response related to SST change. One possible factor contributing to the larger spread is the dipole structure with a strong wetting over central and southern India and drying to the northeast (Figs. 2b, 5d, 6b).

Figure 8 shows the thermodynamic $(\delta \overline{\overline{T H}})$ and dynamic $(\delta \overline{\overline{D Y}})$ components of the mean moisture convergence change $(\delta \overline{\overline{M C}})$, as well as the quadratic term $(\delta \overline{\overline{q u a d}})$
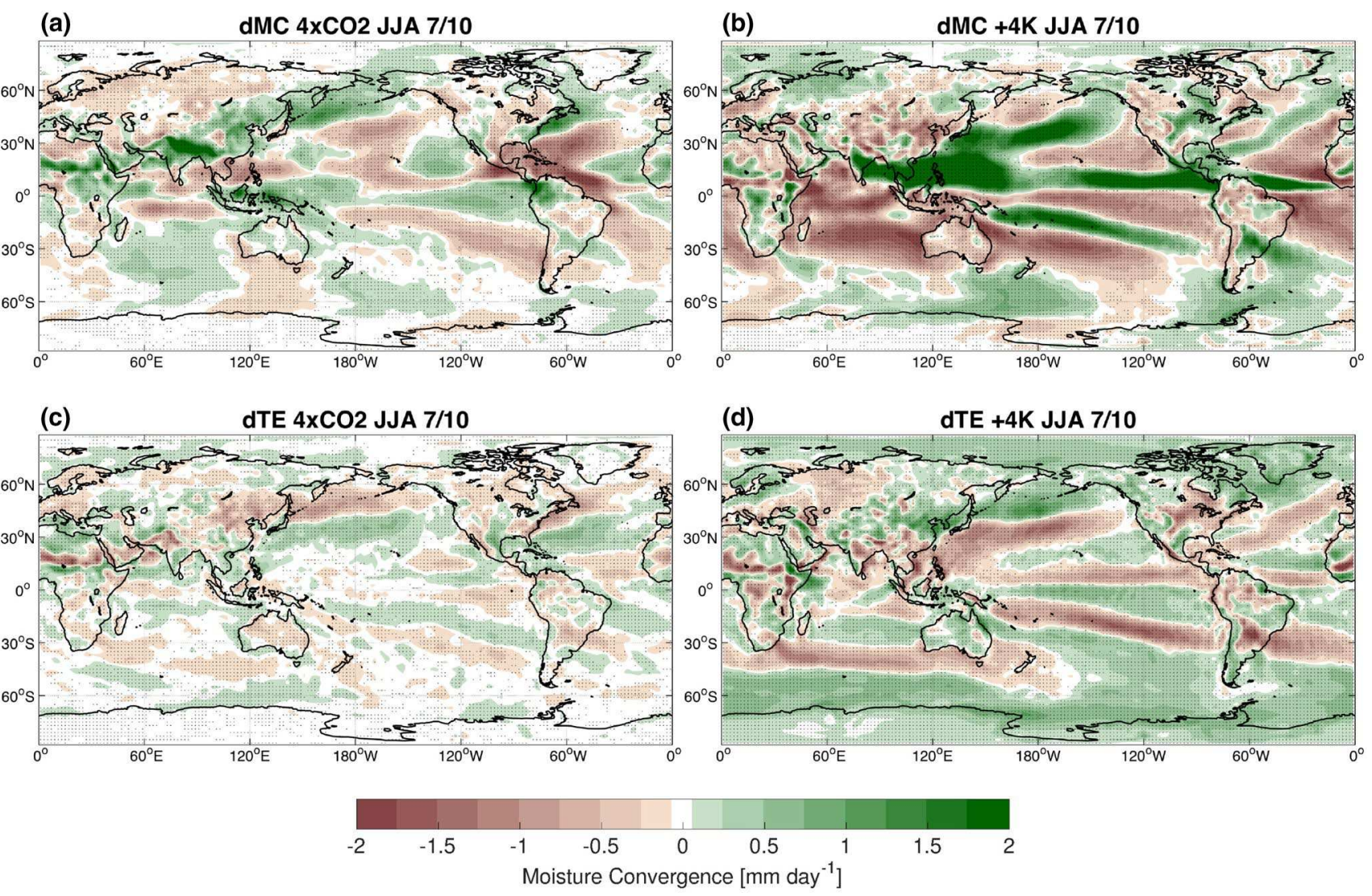

Fig. 6 As in Fig. 5, but for a, b the mean moisture convergence $\delta \overline{\overline{M C}}$ and $\mathbf{c}, \mathbf{d}$ transient eddies $\delta \overline{\overline{T E}}$ 
Fig. 7 Area averaged (landonly) changes of moisture budget terms $(\delta \overline{\bar{P}}, \delta \overline{\bar{E}}, \delta \overline{\overline{(P-E)}}$, $\delta \overline{\overline{M C}}, \delta \overline{\overline{T E}}$ ) over $\mathbf{a}$ India and $\mathbf{b}$ East China for $(\mathrm{red}) 4 \times \mathrm{CO}_{2}$, (blue) $+4 K$, and (green) rcp8.5. Regions defined as in Fig. 1.

The black dots show the 10-model MMMs. Units are $\mathrm{mm}_{\text {day }}{ }^{-1}$
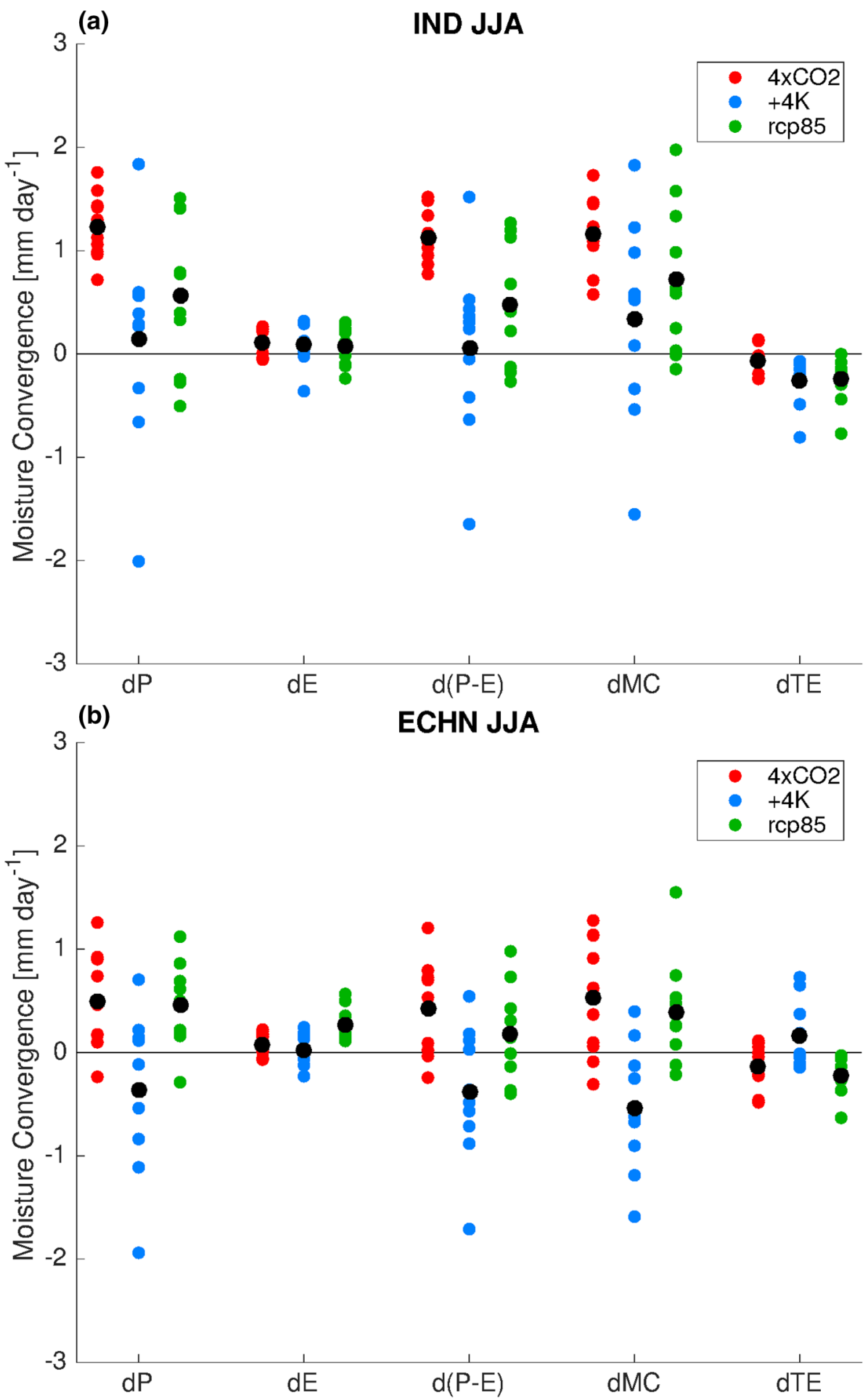

which is small compared to $\delta \overline{\overline{T H}}$ and $\delta \overline{\overline{D Y}}$ in all cases. The area averaged (land-only) changes for India and eastern China are shown in Fig. 9. Similar to the specific humidity response (Fig. 3a, b), SST warming (Fig. 8b) dominates over the direct radiative forcing (Fig. 8a) in terms of thermodynamical changes. Over the monsoon regions, this leads to strongly enhanced wetting for both India (Fig. 9a) and eastern China (Fig. 9b). Dynamical changes, on the other hand, exhibit competing effects in response to direct radiative forcing (Fig. 8c) and SST warming (Fig. 8d) in the northern hemisphere including the North Pacific, North Atlantic, the Asian and African monsoons, and North America. Both the fast and slow responses are robust across the models, as indicated by the stippling (70\% model 
(a)

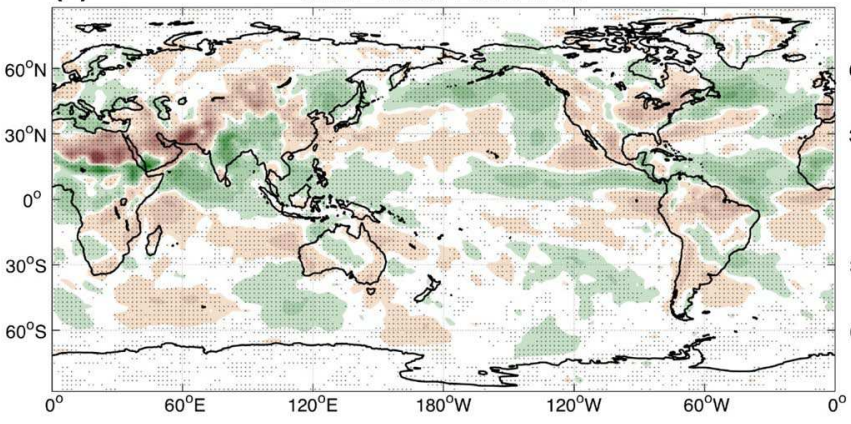

(c)

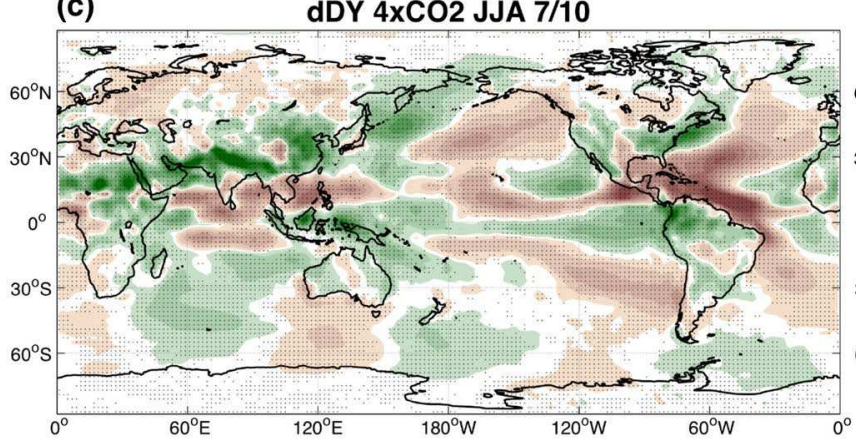

(b)

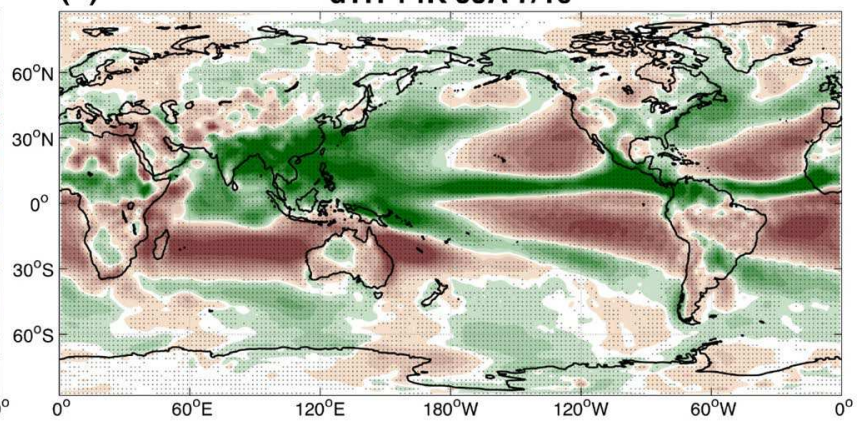

(d)

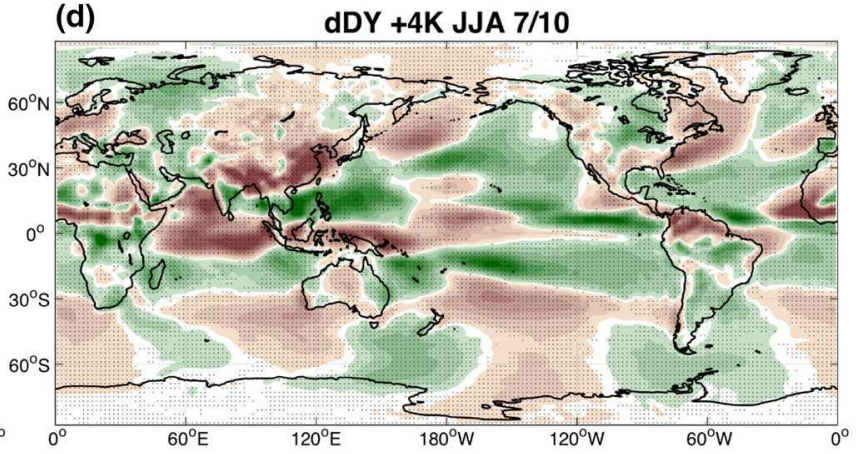

(e)

dquad 4xCO2 JJA 7/10

(f) dquad +4K JJA 7/10

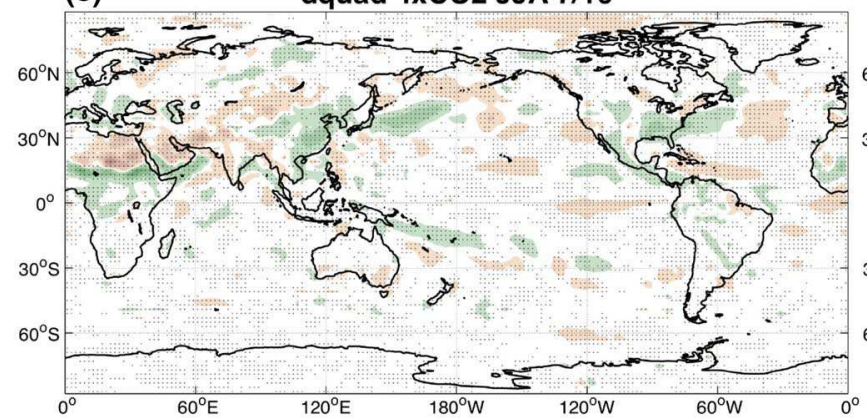
dquad +

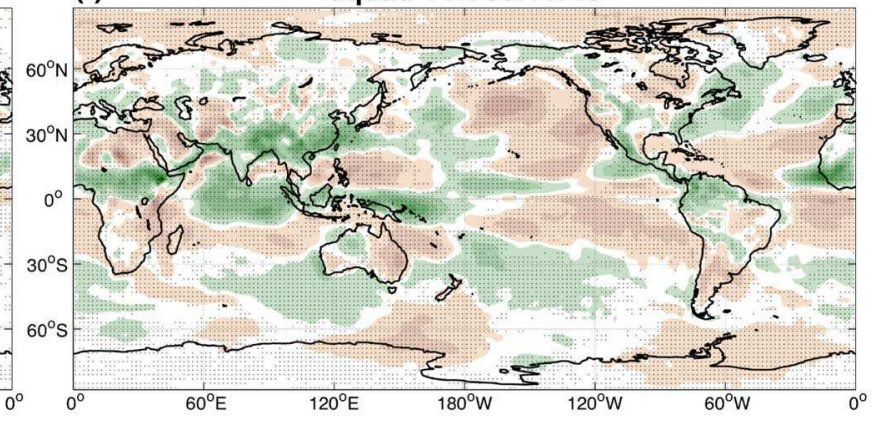

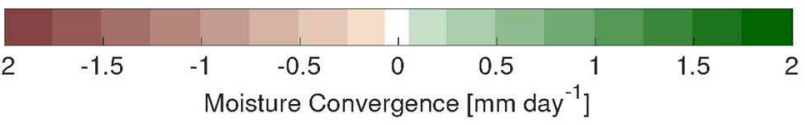

Fig. 8 As in Fig. 5, but for a, b the thermodynamic component $\delta \overline{\overline{T H}}, \mathbf{c}, \mathbf{d}$ the dynamic component $\delta \overline{\overline{D Y}}$, and e, $\mathbf{f}$ the quadratic term $\delta \overline{\overline{q u a d}}$

agreement). The area averaged $\delta \overline{\overline{D Y}}$ for India (Fig. 9a) and eastern China (Fig. 9b) show distinct opposing responses: in all the models, direct radiative effect (red) enhances moisture convergence while SST warming (blue) weakens it. Due to this cancellation, the rcp8.5 response (green) is very weak for the MMM, with a large model spread.

Figures 7 and 9 indicate that the different responses to direct radiative forcing and SST warming of the total mean moisture convergence, and hence precipitation, is mainly caused by the opposing effects of the dynamic component, related to changes in atmospheric circulation. These results are consistent with Shaw and Voigt
(2015), but focusing specifically on the South and East Asian monsoons. Furthermore, the thermodynamic and dynamic effects of SST warming, which evolve on the longer timescale, largely cancel out (also see Shaw and Voigt 2015, Fig. S1g, h). Thus the total mean moisture convergence is dominated by the fast response that occurs shortly after the $\mathrm{CO}_{2}$ increase due to dynamical changes, in agreement with Bony et al. (2013). Note that similar to the precipitation responses, southern India shows different changes in the moisture budget terms as compared to that over northern India and eastern China. 
Fig. 9 As in Fig. 7, but for $\delta \overline{\overline{M C}}, \delta \overline{\overline{T H}}, \delta \overline{\overline{D Y}}$, and $\delta \overline{\overline{q u a d}}$
IND JJA
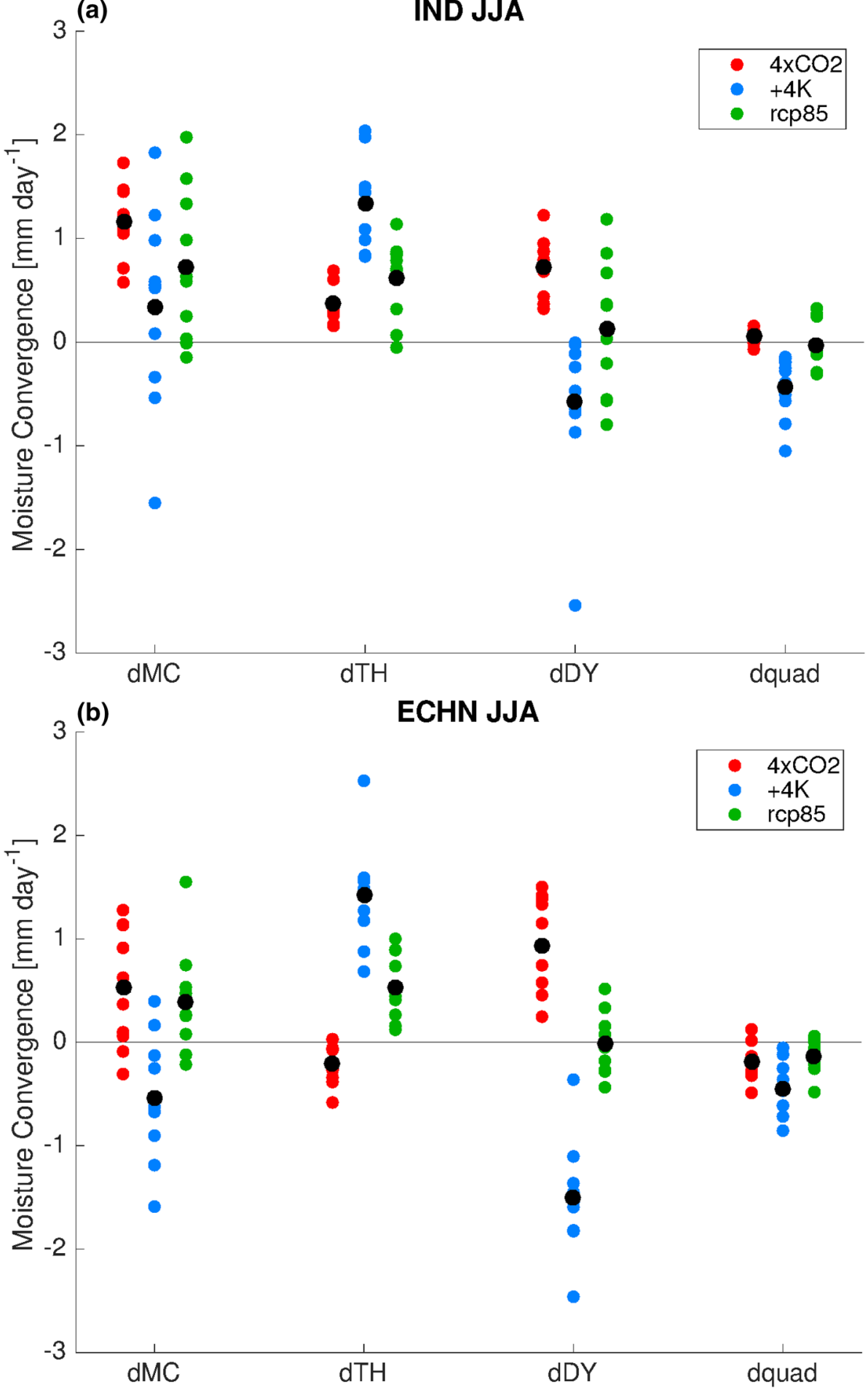

\section{Understanding uncertainties in future monsoon projections}

In Sect. 4, we have shown that the dynamical responses to direct radiative forcing of rising $\mathrm{CO}_{2}$ and subsequent SST warming largely oppose each other over the Asian monsoon region. What does this imply for future monsoon projections? As discussed in Shaw and Voigt (2015), this competing effect may lead to a weak circulation response and lack of consensus among the models. This is confirmed in Fig. 9, in which the 10-model averaged rcp8.5 response of $\delta \overline{\overline{D Y}}$ is almost zero for both regions, with almost equal number of models showing positive and negative sign 
changes. On the other hand, the thermodynamical response, although different in magnitude, is largely consistent in sign across the models. Here we further examine the model discrepancy using the larger ensemble of the 35 CMIP5 coupled models.

Figures 10 and 11 show the linear trend of the thermodynamic and dynamic components of the mean moisture convergence (cf. Li et al. 2015, for detailed definition of the terms) over 2006-2099 under the rcp8.5 scenario for India and eastern China, respectively. The regions and shaded bars are defined as in Fig. 1. While almost all the models display significant wetting trends due to the thermodynamic component (Figs. 10a, 11a), the dynamic component (Figs. 10b, 11b) shows a clear model spread for both regions. The projected rainfall change (Fig. 1) is determined by the relative sign and magnitude of the two components. For example, the group of models with drying trends over India (CMCC-CESM, CMCC-CMS, FIO-ESM, MPI-ESM-LR, MPI-ESM-MR) all show strong dynamical weakening. The MMM trend (black) of the dynamic component is very weak for both regions, consistent with $\mathrm{Li}$ et al. (2015) using the larger monsoon region. There are two reasons for this weak dynamic response: first, the cancellation effect due to inter-model disagreement, as there are models showing significantly increased or decreased moisture convergence; second, the weak responses in some of the models, possibly related to the cancellation effect between direct radiative forcing and SST warming. Thus the uncertainty in future circulation change is related to both model discrepancy and the multiple physical processes involved. While previous studies have suggested that atmospheric circulation dominates the inter-model variations in the tropics focusing on the standard deviation (Kent et al. 2015; Xie et al. 2015), we emphasize here that over the monsoon regions there is substantial uncertainty in both the magnitude and the sign of the dynamical changes.

Our results indicate that the Asian monsoon response to uniform SST warming exhibits a larger model spread as compared to direct radiative forcing in terms of the mean moisture convergence change (Fig. 7), which may come from the cancellation between the thermodynamical and dynamical processes (Fig. 9). Furthermore, SST spatial pattern may not be the dominant cause of the model spread, although it certainly could make a contribution. The large uncertainty in the dynamical contribution to mean moisture convergence as shown in Figs. 10b and $11 \mathrm{~b}$ is largely due to the cancellation of the circulation response to direct radiative forcing and SST warming. The degree of each model's relative importance of the two responses may have led to the large spread in the dynamical component. The weak MMM dynamical response for the rcp8.5 scenario is largely caused by this large model spread rather than a (a) TH trend JJA 2006-2099 CMIP5 rcp85 IND

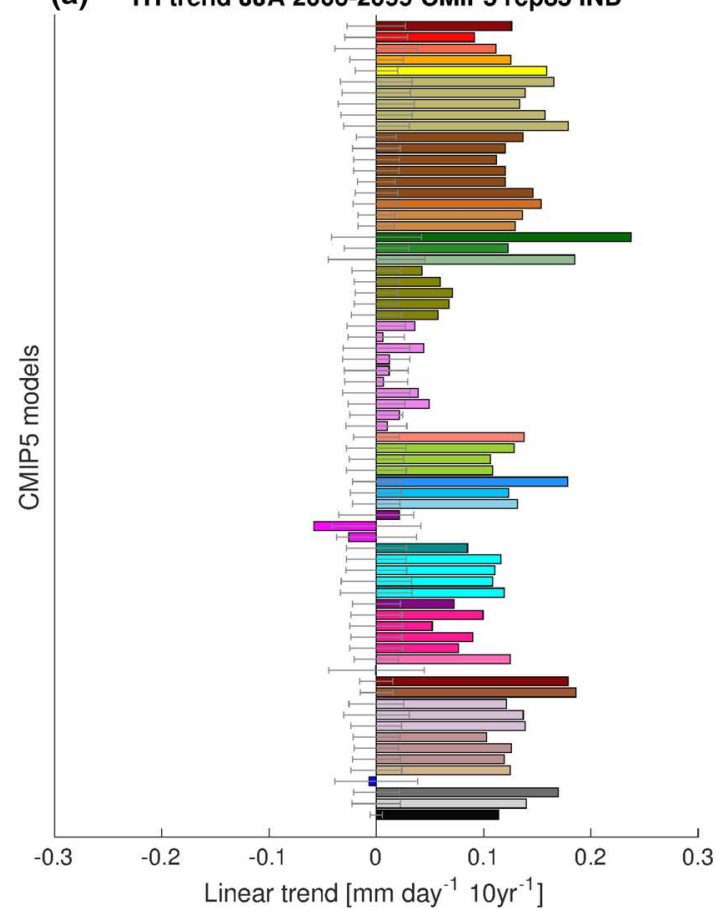

(b) DY trend JJA 2006-2099 CMIP5 rcp85 IND

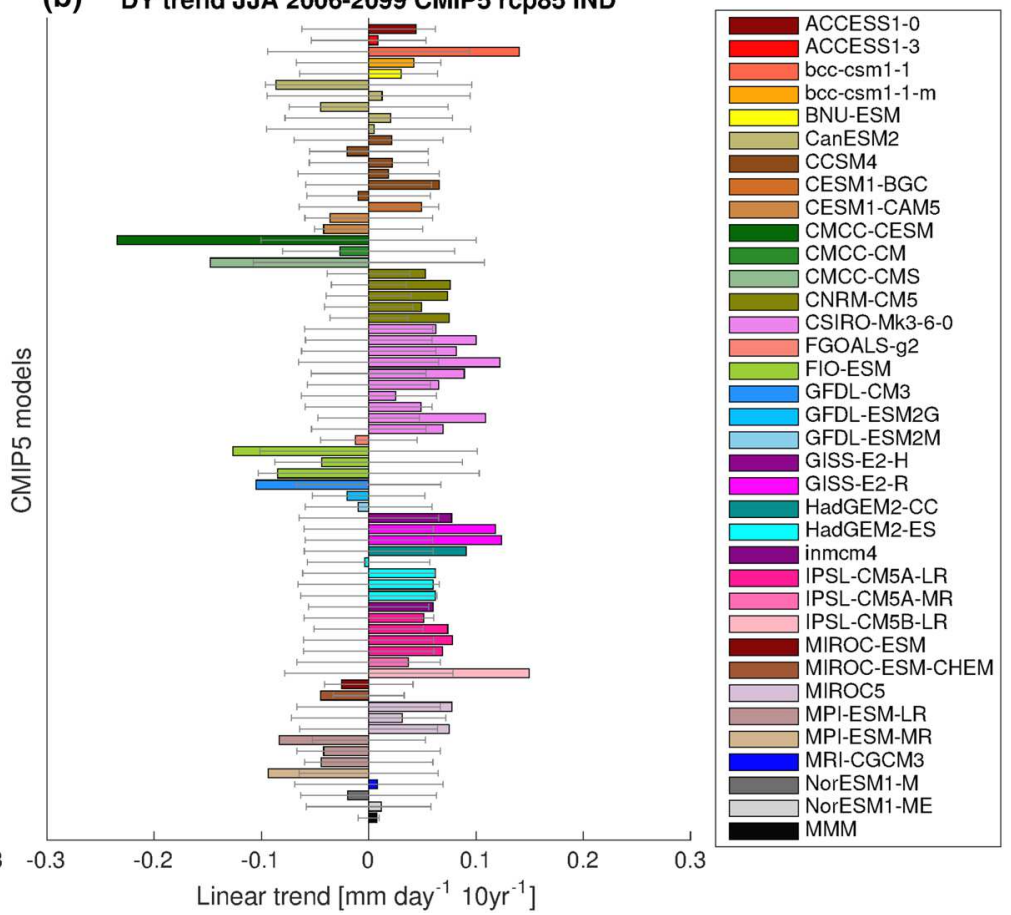

Fig. 10 Linear trend of area averaged a thermodynamic and $\mathbf{b}$ dynamic components of the mean moisture convergence over land in 35 CMIP5 models under the rcp8.5 scenario from 2006 to 2099 for India. The black and shaded bars are defined as in Fig. 1 . Units are mm day ${ }^{-1} 10$ years ${ }^{-1}$ 
(a) TH trend JJA 2006-2099 CMIP5 rCP85 ECHN

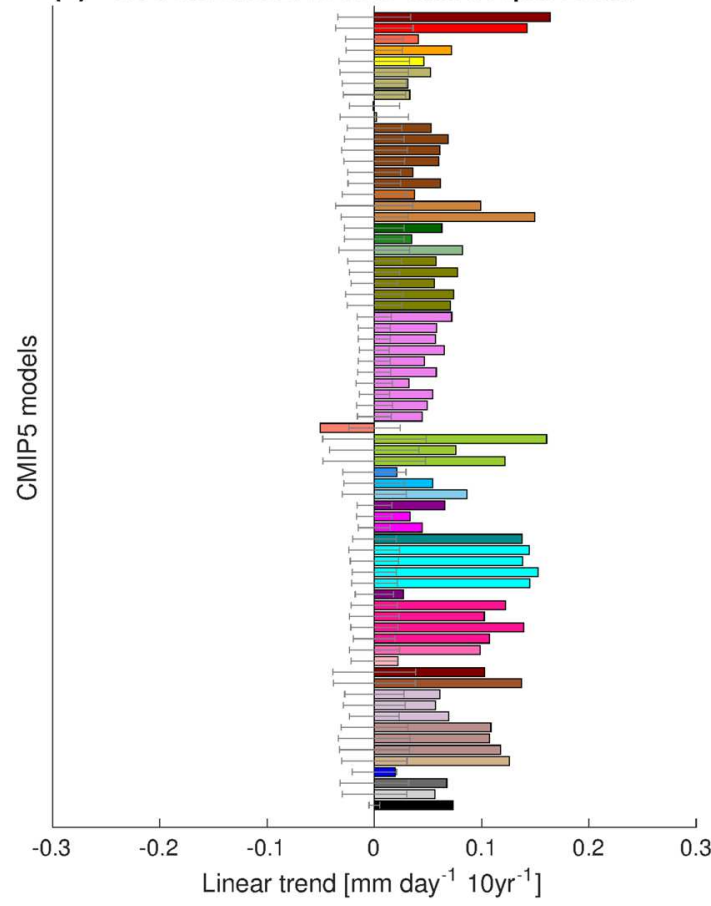

(b) DY trend JJA 2006-2099 CMIP5 rcp85 ECHN

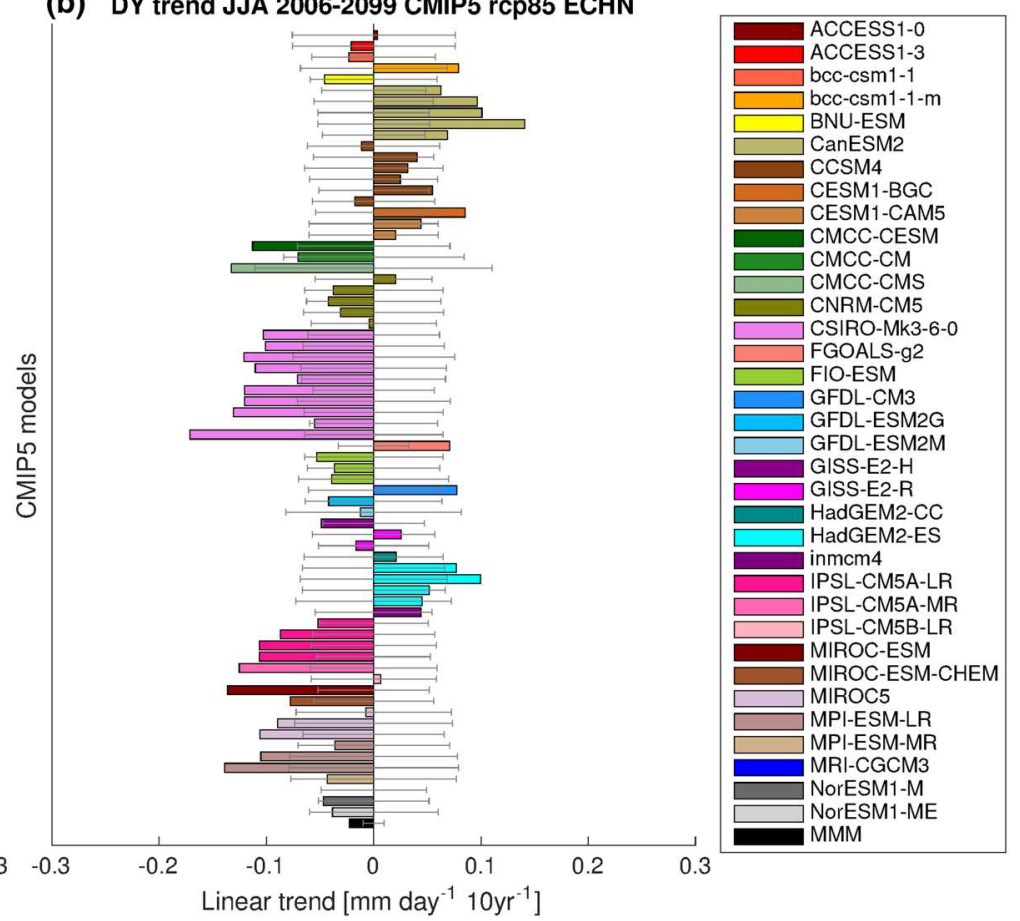

Fig. 11 As in Fig. 10, but for East China

uniformly weak circulation response in individual models. Thus a better projection of the future monsoon rainfall changes depends strongly on reducing the uncertainty in monsoon circulation responses to greenhouse warming.

Previous studies have proposed other possible mechanisms contributing to the uncertainty in regional hydroclimate changes. For example, Bony et al. (2013) suggest the fact that climate models show a large range of climate sensitivity (Andrews et al. 2012) may alter the importance of the thermodynamical changes relative to the dynamical changes and hence the precipitation response. On the contrary, Kent et al. (2015) find that the intermodel uncertainty of tropical rainfall and circulation is not strongly influenced by global mean temperature changes. We have tested the relationship between the thermodynamic and dynamic components and the equilibrium climate sensitivity (ECS) for India and eastern China in the CMIP5 archive (not shown). Results show that while the thermodynamical enhancement of a model is positively correlated with its ECS, the dynamical change only shows a very weak negative correlation with ECS. Other contributing factors to the model uncertainty include the ability of global climate models to simulate the present-day regional climate including monsoon climatology (see "Appendix"), natural variability such as the teleconnection between Asian monsoon and the El Niño-Southern Oscillation (Li and Ting 2015), as well as the possible influence of model resolution. Using a GCM downscaled to a $\sim 35 \mathrm{~km}$ high-resolution over the
South Asian monsoon region, Krishnan et al. (2015) show that the model predicts a persistent drying in the twenty first century, opposing the global model response robust across CMIP5 models. In addition, aerosol forcing represents a major uncertainty for climate prediction (Turner and Annamalai 2012), with opposing effect to GHG forcing on monsoon rainfall ( $\mathrm{Li}$ et al. 2015). Further work is needed to advance the understanding and reduce the uncertainty in future monsoon projections.

\section{Conclusions}

We have examined the regional hydroclimate response to rising GHGs using coupled and idealized atmosphereonly models. The future total rainfall response to increasing $\mathrm{CO}_{2}$ is a combination of the fast component due to direct radiative forcing and the slow component due to SST changes. While it is expected that the fast (slow) component would weaken (enhance) the global hydrological cycle due to associated changes in atmospheric radiative cooling, the Asian monsoon rainfall shows the opposite tendency. The $\mathrm{CO}_{2}$ direct radiative effect leads to a much intensified monsoon rainfall, and SST warming either weakens (eastern China) or slightly intensifies (India) monsoon rainfall. Furthermore, the intensified monsoon rainfall associated with direct radiative forcing is mainly due to circulation changes, rather than through 
thermodynamic changes in the moisture budget sense. The thermodynamic mechanisms, on the other hand, do suggest a much intensified mean moisture convergence due to SST warming, but the enhancement is largely offset by the opposite change in circulation that weakens the monsoon. Overall for most part of the Asian monsoon region (southern India shows different characteristics), the monsoon rainfall changes are dominated by the direct $\mathrm{CO}_{2}$ radiative effect through enhanced monsoon circulation.

The relative effects of direct radiative forcing and SST warming on monsoon circulation has important implications for the uncertainty in future projections. While the thermodynamical response is robust across the models and well understood, there are substantial uncertainties in both the magnitude and the sign of the dynamical changes. For the Asian monsoon, the model spread for the uniform $+4 K$ SST warming case is larger than the corresponding one for $4 \times \mathrm{CO}_{2}$ radiative forcing. The main cause of the model spread in the uniform $+4 K$ SST warming case may come from the cancellation between the dynamical and thermodynamical processes. While the MMM rcp8.5 scenario indicates a weak contribution due to dynamical mechanisms of future monsoon changes ( $\mathrm{Li}$ et al. 2015), the results here indicate that this is largely caused by the large model spread rather than a uniformly weak circulation response in individual models. The lack of consensus among the models and weak MMM responses for the circulation changes in CMIP5 models may be related to the multiple physical processes evolving on different time scales. Understanding the physical mechanisms underlying the circulation changes and the model spread due to uniform SST warming is essential towards constraining the uncertainties in regional climate projection.

Acknowledgements The authors would like to thank Naomi Henderson for helping with the moisture budget calculations, Haibo Liu for downloading and pre-processing the CMIP5 data used in this study, and Michela Biasutti, Yochanan Kushnir, Tiffany Shaw, and Yutian Wu for helpful discussions. We also greatly appreciate the helpful comments from two anonymous reviewers. We acknowledge the World Climate Research Programme's Working Group on Coupled Modelling, which is responsible for CMIP, and we thank the climate modeling groups (listed in Table 1 of this paper) for producing and making available their model output. For CMIP the U.S. Department of Energy's Program for Climate Model Diagnosis and Intercomparison provides coordinating support and led development of software infrastructure in partnership with the Global Organization for Earth System Science Portals. This work was supported by the National Science Foundation Grant AGS16-07348, the Office of Naval Research MURI Grant 511 N00014-12-1-0911, and the Climate Center Award at Lamont-Doherty Earth Observatory, Columbia University. XL was also supported by National Aeronautics and Space Administration (NASA) Headquarters under the NASA Earth and Space Science Fellowship Program-Grant NNX15AP01H

\section{Appendix}

Evaluation of Asian summer monsoon rainfall climatology in coupled and atmosphere-only models

In this section, we provide a brief evaluation of the coupled and atmosphere-only models available for this study. Figure 12 shows the Taylor diagram (Taylor 2001) of JJA rainfall climatology over the Asian monsoon region $\left(5^{\circ} \mathrm{N}-55^{\circ} \mathrm{N}, 60^{\circ} \mathrm{E}-150^{\circ} \mathrm{E}\right.$, land-only) in $35 \mathrm{CMIP} 5 \mathrm{cou}-$ pled models (black) and the 11 AMIP models (red). We used monthly data from two gridded observational datasets for precipitation: the Climate Research Unit (CRU) at the University of East Anglia (UEA) version 3.2 (Harris et al. 2014), and the Global Precipitation Climatology Centre (GPCC) Full Data Product version 6 from the World Climate Research Programme (WCRP) Global Climate Observing System (GCOS) (Schneider et al. 2011). The spatial resolution is $0.5^{\circ} \times 0.5^{\circ}$ for both datasets. We interpolated all observed and modeled data into a $1^{\circ} \times 1^{\circ}$ spatial resolution for direct comparison. The time period for the climatology is 1976-2005 for CMIP5 models and the 30 years available for the AMIP models. CRU is chosen as the reference.

\section{Taylor Diagram P climatology}

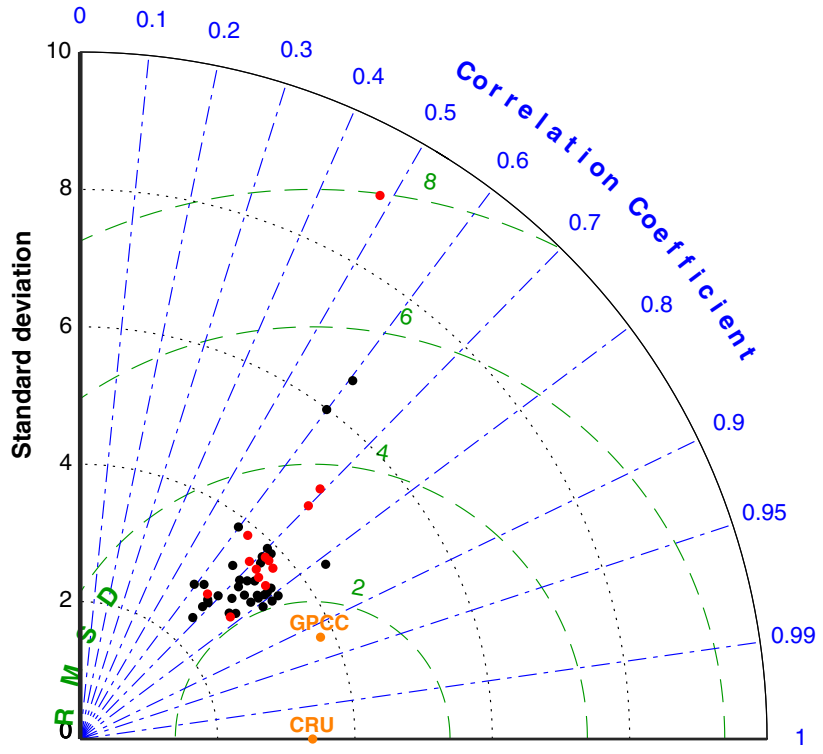

Fig. 12 Taylor diagram showing (blue dot-dashed lines) the spatial pattern correlation coefficient, (black dotted contours) standard deviation, (green dashed contours) the root-mean-square difference $(R M S D)$ for JJA area averaged $\left(5^{\circ} N-55^{\circ} N, 60^{\circ} E-150^{\circ} E\right)$ land precipitation climatology in (black dots) 35 CMIP5 models (1976-2005) and (red dots) 11 AMIP models. Orange dots show observations (CRU, GPCC). CRU is used as the reference field. Rainfall is in $\mathrm{mm} \mathrm{day}^{-1}$ 
The spatial correlations range from 0.6 to 0.8 for most of the coupled models, with comparable standard deviations as observations. The coupled (black) and atmosphere-only (red) models do not exhibit significant differences, suggesting that ocean coupling does not have much effect in simulating monsoon climatology. Only one AGCM (FGOALSg2) produces an unrealistically large standard deviation due to an overestimation of rainfall over India and Indochina (not shown), thus we eliminated this model from further analysis.

\section{References}

Allen MR, Ingram WJ (2002) Constraints on future changes in climate and the hydrologic cycle. Nature 419(6903):224-232. doi:10.1038/nature01092

Andrews T, Forster PM, Gregory JM (2009) A surface energy perspective on climate change. J Clim 22(10):2557-2570. doi:10.1 175/2008JCLI2759.1

Andrews T, Gregory JM, Webb MJ, Taylor KE (2012) Forcing, feedbacks and climate sensitivity in CMIP5 coupled atmosphereocean climate models. Geophys Res Lett 39(9):L09,712. doi:10 .1029/2012GL051607

Bala G, Duffy PB, Taylor KE (2008) Impact of geoengineering schemes on the global hydrological cycle. Proc Natl Acad Sci (USA) 105(22):7664-7669. doi:10.1073/pnas.0711648105

Bala G, Caldeira K, Nemani R (2010) Fast versus slow response in climate change: implications for the global hydrological cycle. Clim Dyn 35(2-3):423-434. doi:10.1007/s00382-009-0583-y

Bollasina MA, Ming Y, Ramaswamy V (2011) Anthropogenic aerosols and the weakening of the South Asian summer monsoon. Science 334(6055):502-505. doi:10.1126/science.1204994

Bony S, Bellon G, Klocke D, Sherwood S, Fermepin S, Denvil S (2013) Robust direct effect of carbon dioxide on tropical circulation and regional precipitation. Nat Geosci 6(6):447-451. doi:10.1038/NGEO1799

Byrne MP, O'Gorman PA (2013) Link between land-ocean warming contrast and surface relative humidities in simulations with coupled climate models. Geophys Res Lett 40(19):5223-5227. doi:10.1002/grl.50971

Chadwick R, Boutle I, Martin G (2013) Spatial patterns of precipitation change in CMIP5: why the rich do not get richer in the tropics. J Clim 26(11):3803-3822. doi:10.1175/JCLI-D-12-00543.1

Chadwick R, Good P, Andrews T, Martin G (2014) Surface warming patterns drive tropical rainfall pattern responses to $\mathrm{CO}_{2}$ forcing on all timescales. Geophys Res Lett 41(2):610-615. doi:10.100 2/2013GL058504

Christensen J, Kumar KK, Aldrian E, An SI, Cavalcanti I, de Castro M, Dong W, Goswami P, Hall A, Kanyanga J, Kitoh A, Kossin J, Lau NC, Renwick J, Stephenson D, Xie SP, Zhou T (2014) Climate phenomena and their relevance for future regional climate change. In: Stocker T, Qin D, Plattner GK, Tignor M, Allen S, Boschung J, Nauels A, Xia Y, Bex V, Midgley P (eds) Climate change 2013: the physical science basis. Contribution of Working Group I to the Fifth Assessment Report of the Intergovernmental Panel on Climate Change, Cambridge University Press, pp 1217-1308

Deser C, Phillips AS (2009) Atmospheric circulation trends, 19502000: the relative roles of sea surface temperature forcing and direct atmospheric radiative forcing. J Clim 22(2):396-413. doi: 10.1175/2008JCLI2453.1
Endo H, Kitoh A (2014) Thermodynamic and dynamic effects on regional monsoon rainfall changes in a warmer climate. Geophys Res Lett 41(5):1704-1711. doi:10.1002/2013GL059158

Grise KM, Polvani LM (2014) The response of midlatitude jets to increased $\mathrm{CO}_{2}$ : distinguishing the roles of sea surface temperature and direct radiative forcing. Geophys Res Lett 41(19):6863-6871. doi:10.1002/2014GL061638

Hansen J, Sato M, Ruedy R (1997) Radiative forcing and climate response. J Geophys Res 102(D6):6831-6864. doi:10.1029/96JD03436

Harris I, Jones P, Osborn T, Lister D (2014) Updated high-resolution grids of monthly climatic observations-the CRU TS3.10 dataset. Int J Climatol 34(3):623-642. doi:10.1002/joc.3711

He J, Soden BJ (2015a) Anthropogenic weakening of the tropical circulation: the relative roles of direct $\mathrm{CO}_{2}$ forcing and sea surface temperature change. J Clim 28(22):8728-8742. doi:10.1175/JCLI-D-15-0205.1

He J, Soden BJ (2015b) Does the lack of coupling in SST-forced atmosphere-only models limit their usefulness for climate change studies? J Clim. doi:10.1175/JCLI-D-14-00597.1

He J, Soden BJ, Kirtman B (2014) The robustness of the atmospheric circulation and precipitation response to future anthropogenic surface warming. Geophys Res Lett 41(7):2614-2622. doi:10.1002/2014GL059435

Held IM, Soden BJ (2006) Robust responses of the hydrological cycle to global warming. J Clim 19(21):5686-5699. doi:10.1175/JCLI3990.1

Joshi M, Gregory J, Webb M, Sexton D, Johns T (2008) Mechanisms for the land/sea warming contrast exhibited by simulations of climate change. Clim Dyn 30(5):455-465. doi:10.1007/s00382-007-0306-1

Kamae Y, Watanabe M, Kimoto M, Shiogama H (2014a) Summertime land-sea thermal contrast and atmospheric circulation over East Asia in a warming climate-part I: past changes and future projections. Clim Dyn 43(9-10):2553-2568. doi:10.1007/s00382-014-2073-0

Kamae Y, Watanabe M, Kimoto M, Shiogama H (2014b) Summertime land-sea thermal contrast and atmospheric circulation over East Asia in a warming climate-part II: importance of $\mathrm{CO}_{2}$-induced continental warming. Clim Dyn 43(9-10):25692583. doi:10.1007/s00382-014-2146-0

Kelley C, Ting M, Seager R, Kushnir Y (2012) The relative contributions of radiative forcing and internal climate variability to the late 20th century winter drying of the Mediterranean region. Clim Dyn 38(9-10):2001-2015. doi:10.1007/ s00382-011-1221-z

Kent C, Chadwick R, Rowell DP (2015) Understanding uncertainties in future projections of seasonal tropical precipitation. J Clim 28(11):4390-4413. doi:10.1175/JCLI-D-14-00613.1

Krishnan R, Sabin T, Vellore R, Mujumdar M, Sanjay J, Goswami B, Hourdin F, Dufresne JL, Terray P (2015) Deciphering the desiccation trend of the South Asian monsoon hydroclimate in a warming world. Clim Dyn 1-21. doi:10.1007/ s00382-015-2886-5

Kumar KK, Kumar KR, Ashrit RG, Deshpande NR, Hansen JW (2004) Climate impacts on Indian agriculture. Int J Climatol 24(11):1375-1393. doi:10.1002/joc.1081

Lau KM, Kim MK, Kim KM (2006) Asian summer monsoon anomalies induced by aerosol direct forcing: the role of the Tibetan Plateau. Clim Dyn 26(7-8):855-864. doi:10.1007/ s00382-006-0114-Z

Li X, Ting M (2015) Recent and future changes in the Asian monsoon-ENSO relationship: natural or forced? Geophys Res Lett 42(9):3502-3512. doi:10.1002/2015GL063557

Li X, Ting M, Li C, Henderson N (2015) Mechanisms of Asian summer monsoon changes in response to anthropogenic 
forcing in CMIP5 models. J Clim 28(10):4107-4125. doi:10.1175/JCLI-D-14-00559.1

Ma J, Xie SP (2013) Regional patterns of sea surface temperature change: a source of uncertainty in future projections of precipitation and atmospheric circulation. J Clim 26(8):2482-2501. doi:10.1175/JCLI-D-12-00283.1

Ma J, Xie SP, Kosaka Y (2012) Mechanisms for tropical tropospheric circulation change in response to global warming. J Clim 25(8):2979-2994. doi:10.1175/JCLI-D-11-00048.1

Mitchell JFB (1983) The seasonal response of a general circulation model to changes in $\mathrm{CO}_{2}$ and sea temperatures. Q J R Meteorol Soc 109(459):113-152. doi:10.1002/qj.49710945906

Mitchell JFB, Wilson CA, Cunnington WM (1987) On $\mathrm{CO}_{2}$ climate sensitivity and model dependence of results. Q J R Meteorol Soc 113(475):293-322. doi:10.1002/qj.49711347517

O'Gorman PA, Allan RP, Byrne MP, Previdi M (2012) Energetic constraints on precipitation under climate change. Surv Geophys 33(3-4):585-608. doi:10.1007/s10712-011-9159-6

Schneider U, Becker A, Finger P, Meyer-Christoffer A, Rudolf B, Ziese M (2011) GPCC full data reanalysis version 6.0 at $0.5^{\circ}$ : monthly land-surface precipitation from rain-gauges built on GTS-based and historic data. doi:10.5676/DWD_GPCC/ FD_M_V6_050

Seager R, Henderson N (2013) Diagnostic computation of moisture budgets in the ERA-Interim reanalysis with reference to analysis of CMIP-archived atmospheric model data. J Clim 26(20):78767901. doi:10.1175/JCLI-D-13-00018.1

Seager R, Ting M, Held I, Kushnir Y, Lu J, Vecchi G, Huang HP, Harnik N, Leetmaa A, Lau NC, Li C, Velez J, Naik N (2007) Model projections of an imminent transition to a more arid climate in southwestern North America. Science 316(5828):11811184. doi:10.1126/science. 1139601

Seager R, Liu H, Henderson N, Simpson I, Kelley C, Shaw T, Kushnir Y, Ting M (2014) Causes of increasing aridification of the Mediterranean region in response to rising greenhouse gases. J Clim 27(12):4655-4676. doi:10.1175/JCLI-D-13-00446.1

Shaw TA, Voigt A (2015) Tug of war on summertime circulation between radiative forcing and sea surface warming. Nat Geosci 8(7):560-566. doi:10.1038/ngeo2449

Shindell DT, Lamarque JF, Schulz M, Flanner M, Jiao C, Chin M, Young PJ, Lee YH, Rotstayn L, Mahowald N, Milly G, Faluvegi G, Balkanski Y, Collins WJ, Conley AJ, Dalsoren S, Easter R,
Ghan S, Horowitz L, Liu X, Myhre G, Nagashima T, Naik V, Rumbold ST, Skeie R, Sudo K, Szopa S, Takemura T, Voulgarakis A, Yoon JH, Lo F (2013) Radiative forcing in the ACCMIP historical and future climate simulations. Atmos Chem Phys 13(6):2939-2974. doi:10.5194/acp-13-2939-2013

Takahashi K (2009) Radiative constraints on the hydrological cycle in an idealized radiative-convective equilibrium model. J Atmos Sci 66(1):77-91. doi:10.1175/2008JAS2797.1

Taylor KE (2001) Summarizing multiple aspects of model performance in a single diagram. J Geophys Res 106(D7):7183-7192. doi:10.1029/2000JD900719

Taylor KE, Stouffer RJ, Meehl GA (2012) An overview of CMIP5 and the experiment design. Bull Am Meteorol Soc 93(4):485498. doi:10.1175/BAMS-D-11-00094.1

Trenberth KE, Guillemot CJ (1995) Evaluation of the global atmospheric moisture budget as seen from analyses. J Clim 8(9):2255-2272. doi:10.1175/1520-0442(1995) $008<2255$ :EOTGAM $>2.0 . \mathrm{CO} ; 2$

Turner AG, Annamalai H (2012) Climate change and the South Asian summer monsoon. Nat Clim Chang 2(8):587-595. doi:10.1038/ nclimate 1495

Vecchi GA, Soden BJ (2007) Global warming and the weakening of the tropical circulation. J Clim 20(17):4316-4340. doi:10.1175/ JCLI4258.1

Wang B, Yim SY, Lee JY, Liu J, Ha KJ (2014) Future change of Asian-Australian monsoon under RCP 4.5 anthropogenic warming scenario. Clim Dyn 42(1-2):83-100. doi:10.1007/ s00382-013-1769-x

Xie SP, Deser C, Vecchi GA, Ma J, Teng H, Wittenberg AT (2010) Global warming pattern formation: sea surface temperature and rainfall. J Clim 23(4):966-986. doi:10.1175/2009JCLI3329.1

Xie SP, Deser C, Vecchi GA, Collins M, Delworth TL, Hall A, Hawkins E, Johnson NC, Cassou C, Giannini A, Watanabe M (2015) Towards predictive understanding of regional climate change. Nat Clim Chang 5(10):921-930. doi:10.1038/nclimate2689

Yang F, Kumar A, Schlesinger ME, Wang W (2003) Intensity of hydrological cycles in warmer climates. J Clim 16(14):24192423. doi: $10.1175 / 2779.1$

Zhang X, He J, Zhang J, Polyakov I, Gerdes R, Inoue J, Wu P (2013) Enhanced poleward moisture transport and amplified northern high-latitude wetting trend. Nat Clim Chang 3(1):47-51. doi:10.1038/nclimate1631 